\title{
醏
}

Subdirección General de Evaluación de Instrumentos de Politica Comercial*

\section{LA EVOLUCIÓN DEL COMERCIO EXTERIOR ESPAÑOL DE ALTA TECNOLOGÍA}

El análisis de los sectores y productos del alto contenido tecnológico, debido al elevado valor añadido que generan y a sus beneficiosos efectos arrastre para la economía, han captado el interés de los responsables de diseñar la política económica de cada país. Así, existe una elevada demanda de estadísticas relacionadas con la tecnología que es satisfecha por diversos organismos de ámbito supranacional, entre otros, la OCDE y Eurostat, y, para el caso español, por el Instituto Nacional de Estadística (INE). El presente artículo tiene por objeto realizar un análisis descriptivo de las estadísticas de comercio exterior de productos de alta tecnología, así como de las principales variables económicas de los sectores de tecnología alta y media-alta publicados por el INE y Eurostat.

Palabras clave: comercio exterior, exportaciones, importaciones, alta tecnología.

Clasificación JEL: F14, F19.

\section{Introducción: el comercio exterior español de alta tecnología}

Los trabajos metodológicos realizados en el seno de la OCDE a finales del siglo pasado marcaron las bases para el desarrollo de las estadísticas que analizan la situación tecnológica de un determinado país, mediante el análisis de sus sectores y productos. A nivel de la Unión Europea (UE) estos trabajos fueron adaptados e incorporados en primera instancia por Eurostat y de forma derivada por los organismos de estadística de los Estados miembros, el INE en el caso de España.

El conocimiento de la situación actual y de la evolución reciente de los sectores y productos de alta tecnología es un elemento clave

\footnotetext{
* Este artículo ha sido elaborado por Albert Vinaixa Roselló Diplomado Comercial del Estado.

Versión de julio de 2016.
}

para los responsables de diseñar la política económica de un país, dados los importantes efectos arrastre sobre la economía en su conjunto y para el favorecimiento de un crecimiento económico más robusto y sostenible en el tiempo.

Otro elemento facilitador tanto del progreso técnico como del crecimiento económico es el comercio exterior, como queda demostrado con el elevado grado de apertura de las economías más avanzadas.

En este artículo se realizará un recorrido descriptivo por las estadísticas de alta tecnología de España publicadas por el INE, así como las publicadas por Eurostat con el fin de hacer análisis comparativos respecto al resto de países de la UE.

En el análisis de las estadíticas de alta tecnología se distinguen dos enfoques: el enfoque sectorial que se centra en las principales variables económicas de las empresas clasificadas dentro de los sectores de tecnología alta y $\triangleright$ 
media-alta atendiendo a la intensidad de $\mathrm{I}+\mathrm{D}$ (investigación y desarrollo), y el enfoque por productos, que ofrece datos de producción y comercio exterior de los productos de alta tecnología.

Si bien el presente artículo se centra en el análisis del comercio exterior español de productos de alta tecnología, siguiendo para ello el enfoque por productos, se ha considerado importante presentar, en primer lugar, algunas de las principales variables económicas y de empleo de los sectores de tecnología alta y mediaalta según el enfoque sectorial.

El periodo analizado varía en función del último año disponible, pero se ha elegido el año 2008 como inicio en todos los casos, ya que fue el del comienzo de la crisis y previo al fuerte bache que experimentó el comercio en el año 2009. En 2008 se alcanzó el máximo de las exportaciones hasta esa fecha, 189.228 millones de euros, máximo que se ha ido superando cada año desde 2011, mientras que en las importaciones se registró el segundo mayor valor de todos los tiempos, 283.388 millones de euros, tras el del año 2007.

\section{Enfoque sectorial}

El INE distingue en el enfoque sectorial los sectores manufactureros de alta tecnología y tecnología media-alta, así como los servicios de alta tecnología, que no serán objeto de este artículo. Para la clasificación de los sectores, el INE se basa en las líneas marcadas por los trabajos metodológicos realizados en el seno de la OCDE, utilizando la clasificación de Naciones Unidas ISIC (International Standard Industrial Classification of All Economic Activities), así como las adaptaciones que se han realizado de los mismos en el ámbito de Eurostat. Para ello, se establecen las correspondencias con una agrupación de sectores de la Clasificación Nacional de Actividades Económicas (CNAE-2009) (Anexo 1).

\subsection{Principales variables económicas y empleo de España}

Los datos correspondientes a España se obtienen en su mayor parte de los indicadores del sector de alta tecnología que publica el INE desde 2002 con periodicidad anual. Se trata de una estadística de síntesis que proporciona datos sobre variables económicas y de empleo de los sectores de tecnología de alta y mediaalta, así como de la producción y el comercio exterior de productos de alta tecnología en España, que se analizarán en el punto 3. El 24 de febrero de 2016 el INE publicó los datos correspondientes al año 2014.

Entre las principales variables que el INE incluye en los indicadores de los sectores de tecnología alta y media-alta se encuentran el número de empresas, la cifra de negocios, el valor añadido y el número de ocupados, que se analizarán en este apartado. EI INE ofrece más indicadores, entre otros, los datos desagregados por comunidades autónomas, los ocupados por sexo y edad, la ganancia media e indicadores de $I+D$, que se pueden consultar en la sección de indicadores de alta tecnología del INE.

Los indicadores de alta tecnología en el enfoque sectorial se nutren en gran parte de la Encuesta Industrial de Empresas del INE. En esta encuesta se han producido diferentes rupturas de serie en el periodo analizado (2008-2014): el cambio de la CNAE-1993 a la CNAE-2009 en 2009 y la ampliación de ámbito poblacional en 2011 y 2013 y territorial en 2013. Por ello, las comparativas de la evolución temporal deben tomarse con mucha cautela.

En 2014 había 18.894 empresas en España pertenecientes a los sectores de tecnología alta y media-alta, el 10,6 por 100 del total de empresas de la industria y tan solo el 0,6 por 100 del total de empresas de la economía (Cuadro 1). El peso de empresas de tecnología alta y media-alta ha caído en el total de la $\square$ 


\section{LA EVOLUCIÓN DEL COMERCIO EXTERIOR ESPAÑOL DE ALTA TECNOLOGÍA}

\begin{tabular}{|c|c|c|c|c|c|c|c|}
\hline \multicolumn{8}{|c|}{$\begin{array}{c}\text { CUADRO } 1 \\
\text { NÚMERO DE EMPRESAS }\end{array}$} \\
\hline Sector & 2008 & 2009 & 2010 & 2011 & 2012 & 2013 & 2014 \\
\hline $\begin{array}{l}\text { Tecnología alta y media-alta } \\
\text { Tecnología alta. } \\
\text { Tecnología media-alta. }\end{array}$ & $\begin{array}{r}17.085 \\
2.156 \\
14.929\end{array}$ & $\begin{array}{r}16.414 \\
1.955 \\
14.459\end{array}$ & $\begin{array}{r}15.875 \\
1.947 \\
13.928\end{array}$ & $\begin{array}{r}14.768 \\
1.833 \\
12.935\end{array}$ & $\begin{array}{r}14.437 \\
1.738 \\
12.699\end{array}$ & $\begin{array}{r}19.556 \\
2.781 \\
16.775\end{array}$ & $\begin{array}{r}19.894 \\
2.750 \\
17.144\end{array}$ \\
\hline Total industria (EIE) & 149.601 & 136.558 & 135.966 & 129.332 & 121.576 & 191.075 & 188.470 \\
\hline Total economía (DIRCE) & 3.422.239 & 3.355 .830 & 3.291 .263 & 3.250 .576 & 3.199.617 & 3.146 .570 & 3.119.310 \\
\hline 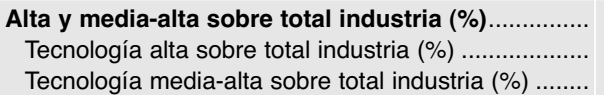 & $\begin{array}{r}11,4 \\
1,4 \\
10,0\end{array}$ & $\begin{array}{r}12,0 \\
1,4 \\
10,6\end{array}$ & $\begin{array}{r}11,7 \\
1,4 \\
10,2\end{array}$ & $\begin{array}{r}11,4 \\
1,4 \\
10,0\end{array}$ & $\begin{array}{r}11,9 \\
1,4 \\
10,4\end{array}$ & $\begin{array}{r}10,2 \\
1,5 \\
8,8\end{array}$ & $\begin{array}{r}10,6 \\
1,5 \\
9,1\end{array}$ \\
\hline Alta y media-alta sobre total economía (\%) ............... & 0,5 & 0,5 & 0,5 & 0,5 & 0,5 & 0,6 & 0,6 \\
\hline
\end{tabular}

\begin{tabular}{|c|c|c|c|c|c|c|c|}
\hline \multicolumn{8}{|c|}{$\begin{array}{l}\text { CUADRO } 2 \\
\text { CIFRA DE NEGOCIOS } \\
\text { (Millones de euros) }\end{array}$} \\
\hline Sector & 2008 & 2009 & 2010 & 2011 & 2012 & 2013 & 2014 \\
\hline $\begin{array}{l}\text { Tecnología alta y media-alta } \\
\text { Tecnología alta } \\
\text { Tecnología media-alta }\end{array}$ & $\begin{array}{r}180.675,0 \\
29.808,7 \\
150.866,3\end{array}$ & $\begin{array}{r}142.150,5 \\
25.334,8 \\
116.815,7\end{array}$ & $\begin{array}{r}152.394,1 \\
25.410,5 \\
126.983,6\end{array}$ & $\begin{array}{r}154.705,2 \\
23.316,6 \\
131.388,6\end{array}$ & $\begin{array}{r}148.898,9 \\
22.659,7 \\
126.239,1\end{array}$ & $\begin{array}{r}150.237,9 \\
24.130,7 \\
126.107,2\end{array}$ & $\begin{array}{r}158.058,3 \\
24.508,6 \\
133.549,8\end{array}$ \\
\hline Total industria (EIE) & $628.903,1$ & $496.295,8$ & $520.864,5$ & $575.046,8$ & $570.984,4$ & $562.350,7$ & $571.921,6$ \\
\hline 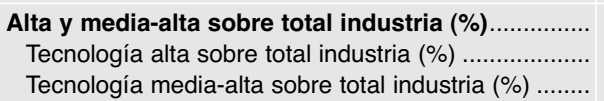 & $\begin{array}{r}28,7 \\
4,7 \\
24,0\end{array}$ & $\begin{array}{r}28,6 \\
5,1 \\
23,5\end{array}$ & $\begin{array}{r}29,3 \\
4,9 \\
24,4\end{array}$ & $\begin{array}{r}26,9 \\
4,1 \\
22,8\end{array}$ & $\begin{array}{r}26,1 \\
4,0 \\
22,1\end{array}$ & $\begin{array}{r}26,7 \\
4,3 \\
22,4\end{array}$ & $\begin{array}{r}27,6 \\
4,3 \\
23,4\end{array}$ \\
\hline
\end{tabular}

\begin{tabular}{|c|c|c|c|c|c|c|c|}
\hline \multicolumn{8}{|c|}{$\begin{array}{c}\text { CUADRO } 3 \\
\text { VALOR AÑADIDO } \\
\text { (Millones de euros) }\end{array}$} \\
\hline Sector & 2008 & 2009 & 2010 & 2011 & 2012 & 2013 & 2014 \\
\hline Tecnología alta y media-alta & $39.755,7$ & $32.175,2$ & $35.180,8$ & $34.627,0$ & $32.797,7$ & $33.303,2$ & $36.428,6$ \\
\hline Tecnología alta & $7.803,3$ & $6.777,8$ & $7.202,7$ & $6.749,3$ & $6.958,0$ & $7.539,8$ & $8.182,8$ \\
\hline Tecnología media-alta & $31.952,4$ & $25.397,5$ & $27.978,1$ & $27.877,6$ & $25.839,7$ & $25.763,4$ & $28.245,8$ \\
\hline Total industria (EIE) & nd & nd & nd & nd & 125.417 & 124.468 & 127.547 \\
\hline 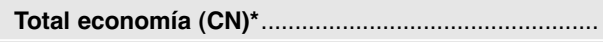 & 1.025 .672 & 1.006 .122 & 989.913 & 983.721 & 957.140 & 941.293 & 948.309 \\
\hline Alta y media-alta sobre total industria (\%) $\ldots \ldots \ldots \ldots \ldots$ & nd & nd & nd & nd & 26,2 & 26,8 & 28,6 \\
\hline Tecnología alta sobre total industria (\%) …….............. & nd & nd & nd & nd & 5,5 & 6,1 & 6,4 \\
\hline Tecnología media-alta sobre total industria (\%) ........ & nd & nd & nd & nd & 20,6 & 20,7 & 22,1 \\
\hline Alta y media-alta sobre total economía (\%) …............... & 3,9 & 3,2 & 3,6 & 3,5 & 3,4 & 3,5 & 3,8 \\
\hline $\begin{array}{l}\text { nd: no disponible. } \\
{ }^{*} \text { A precios básicos. }\end{array}$ & & & & & & & \\
\hline
\end{tabular}

industria desde el 11,4 por 100 alcanzado en 2008, pero en cambio ha aumentado con respecto al total de empresas de la economía desde el 0,5 por 100 en 2008. Dentro de las empresas de tecnología alta y media-alta, las de tecnología media-alta son mayoría, 86,2 por 100 en 2014, frente al 13,8 por 100 de las de alta tecnología.

Las ventas comerciales netas de bienes (cifra de negocios) de las empresas de los sectores manufactureros de tecnología alta y media alta alcanzaron en 2014 los $158.058,3$ millones de euros, el 27,6 por 100 de las ventas totales de la industria, porcentaje inferior al 28,7 por 100 que representaron en 2008 (Cuadro 2).

El valor añadido bruto al coste de los factores, renta bruta de las actividades de explotación que queda para la retribución de los factores productivos, de las empresas de los sectores de tecnología alta y media-alta alcanzó los $36.428,6$ millones de euros en 2014 , el 28,6 por 100 del total de la industria (Cuadro 3). 


\begin{tabular}{|c|c|c|c|c|c|c|c|}
\hline \multicolumn{8}{|c|}{$\begin{array}{c}\text { CUADRO } 4 \\
\text { PERSONAS OCUPADAS }\end{array}$} \\
\hline Sector & 2008 & 2009 & 2010 & 2011 & 2012 & 2013 & 2014 \\
\hline 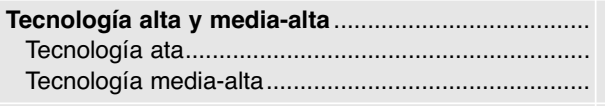 & $\begin{array}{l}824.400 \\
143.700 \\
680.700\end{array}$ & $\begin{array}{l}727.600 \\
135.900 \\
591.700\end{array}$ & $\begin{array}{l}714.400 \\
147.200 \\
567.200\end{array}$ & $\begin{array}{l}688.300 \\
142.100 \\
546.200\end{array}$ & $\begin{array}{l}661.400 \\
135.000 \\
526.400\end{array}$ & $\begin{array}{l}672.100 \\
147.300 \\
524.800\end{array}$ & $\begin{array}{l}679.300 \\
136.400 \\
542.900\end{array}$ \\
\hline Total industria (EIE).. & 2.514.397 & 2.199 .532 & 2.133 .618 & 2.049.195 & 1.922.272 & 1.949.194 & 1.931.972 \\
\hline 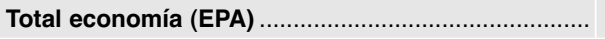 & 20.469.700 & 19.106.900 & 18.724 .500 & 18.421 .400 & 17.632 .700 & 17.139 .000 & 17.344.200 \\
\hline $\begin{array}{l}\text { Alta y media-alta sobre total industria (\%) ............... } \\
\text { Tecnología alta sobre total industria }(\%) \text {................. } \\
\text { Tecnología media-alta sobre total industria (\%) ........ }\end{array}$ & $\begin{array}{r}32,8 \\
5,7 \\
27,1\end{array}$ & $\begin{array}{r}33,1 \\
6,2 \\
26,9\end{array}$ & $\begin{array}{r}33,5 \\
6,9 \\
26,6\end{array}$ & $\begin{array}{r}33,6 \\
6,9 \\
26,7\end{array}$ & $\begin{array}{r}34,4 \\
7,0 \\
27,4\end{array}$ & $\begin{array}{r}34,5 \\
7,6 \\
26,9\end{array}$ & $\begin{array}{r}35,2 \\
7,1 \\
28,1\end{array}$ \\
\hline Alta y media-alta sobre total economía (\%) ............ & 4,0 & 3,8 & 3,8 & 3,7 & 3,8 & 3,9 & 3,9 \\
\hline
\end{tabular}

Las empresas de los sectores manufactureros de tecnología alta y media-alta emplearon a 679.300 personas en 2014 , el 35,2 por 100 del total de la industria o el 3,9 por 100 del total de ocupados de la economía. El número de ocupados de estos sectores se ha ido reduciendo de 2008 a 2012, para volver a crecer a partir de entonces. En cambio, el peso sobre el total de la industria se ha ido incrementando en todos los años desde 2008, lo que indica el mejor comportamiento en cuanto a empleo de las empresas de estos sectores con respecto a las del conjunto de la industria. Dentro de estos sectores, el de tecnología alta se ha mostrado más estable en el tiempo (Cuadro 4).

\subsection{Datos comparativos de la Unión Europea}

Eurostat publica los datos para los países de la UE, lo que permite hacer un análisis con datos homogéneos de la situación de España en comparación con la del resto de países de la UE. La clasificación empleada por Eurostat se basa también en los estudios metodológicos de la OCDE con correspondencias entre el ISIC y con la Statistical classification of economic activities in the European Community (NACE revisión 2). Los datos ofrecidos por Eurostat pueden diferir de los del INE sobre todo por posibles diferencias metodológicas de ámbito poblacional, si bien se han ido reduciendo a lo largo del tiempo.

\subsubsection{Empresas manufactureras}

De acuerdo con los datos de Eurostat, España era en 2013 el $5^{\circ}$ país de la UE con el mayor número de empresas del sector manufacturero ${ }^{1}$ con 168.935 empresas, un 18,6 por 100 menos que en 2008. Encabezando la lista se sitúa Italia con 407.344 empresas, si bien su número se ha reducido en un 11,4 por 100 con respecto a 2008. Le sigue Francia con 226.372 empresas, un 7,0 por 100 más con respecto a 2008, y Alemania con 202.824 empresas, incrementando su número en un 3,8 por 100 con respecto a 2008. Polonia antecede a España en el ranking con 174.414 empresas, un 8,0 por 100 menos que en 2008 . En el conjunto de la UE el número de empresas manufactureras se ha reducido un 3,4 por 100 con respecto al valor de 2008 (Cuadro 5).

\subsubsection{Empresas manufactureras de alta tecnología}

España era en 2013 el $7^{\circ}$ país de la UE con el mayor número de empresas manufactureras $\triangleright$

\footnotetext{
1 El sector manufacturero es un término más restringido que el de la industria, por cuanto la industria incluye además del sector manufacturero, las industrias extractivas, así como las de suministro de energía eléctrica, gas, vapor, aire acondicionado, agua, saneamiento, residuos y descontaminación.
} 


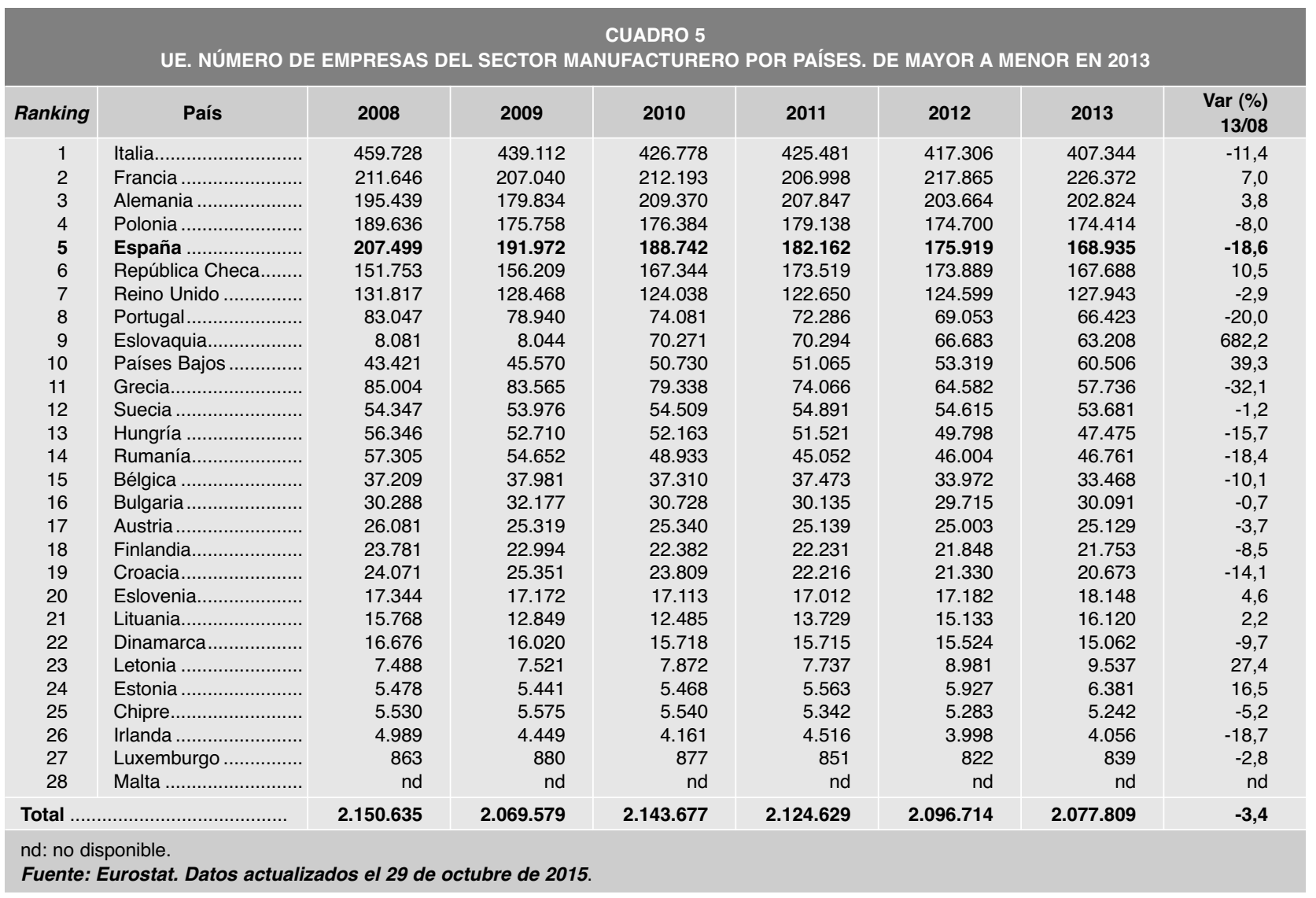

CUADRO 6

UE. NÚMERO DE EMPRESAS DEL SECTOR MANUFACTURERO DE ALTA TECNOLOGÍA POR PAísES. DE MAYOR A MENOR EN 2013

\begin{tabular}{|c|c|c|c|c|c|c|c|c|}
\hline Ranking & País & 2008 & 2009 & 2010 & 2011 & 2012 & 2013 & $\begin{array}{c}\text { Var (\%) } \\
13 / 08\end{array}$ \\
\hline 1 & Alemania ........................ & 7.790 & 8.759 & 8.975 & 8.536 & 8.247 & 8.713 & 11,8 \\
\hline 2 & Reino Unido ................. & 7.479 & 7.436 & 6.831 & 6.569 & 6.385 & 6.528 & $-12,7$ \\
\hline 3 & 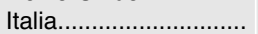 & 7.379 & 6.909 & 6.680 & 6.272 & 5.984 & 5.683 & $-23,0$ \\
\hline 4 & 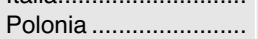 & 2.382 & 2.939 & 3.097 & 3.106 & 3.033 & 3.432 & 44,1 \\
\hline 5 & República Checa........... & 3.737 & 3.822 & 3.553 & 3.477 & 3.441 & 3.405 & $-8,9$ \\
\hline 6 & Francia ........................... & 4.538 & 4.264 & 3.403 & 3.155 & 3.227 & 3.309 & $-27,1$ \\
\hline 7 & 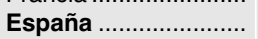 & 3.219 & 3.037 & 3.027 & 2.956 & 2.815 & 2.704 & $-16,0$ \\
\hline 8 & 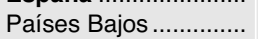 & 1.348 & 1.425 & 1.592 & 1.633 & 1.640 & 1.807 & 34,1 \\
\hline 9 & 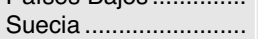 & 1.975 & 1.917 & 1.875 & 1.843 & 1.816 & 1.763 & $-10,7$ \\
\hline 10 & 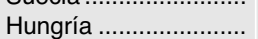 & 2.684 & 1.737 & 1.749 & 1.688 & 1.604 & 1.548 & $-42,3$ \\
\hline 11 & Rumania....................... & 1.309 & 1.187 & 1.092 & 951 & 985 & 980 & $-25,1$ \\
\hline 12 & 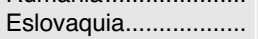 & 268 & nd & 818 & 830 & 755 & 759 & 183,2 \\
\hline 13 & Austria & 672 & 645 & 648 & 649 & 672 & 668 & $-0,6$ \\
\hline 14 & 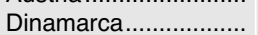 & 641 & 638 & 630 & 660 & 669 & 654 & 2,0 \\
\hline 15 & 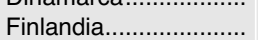 & 627 & 597 & 597 & 603 & 602 & 597 & $-4,8$ \\
\hline 16 & 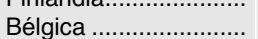 & nd & 826 & nd & nd & 611 & 583 & nd \\
\hline 17 & 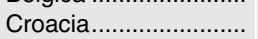 & 845 & 886 & 795 & 748 & 713 & 573 & $-32,2$ \\
\hline 18 & 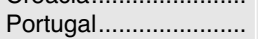 & 555 & 512 & 479 & 466 & 448 & 494 & $-11,0$ \\
\hline 19 & 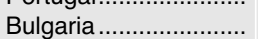 & 448 & 448 & 424 & 407 & 428 & 438 & $-2,2$ \\
\hline 20 & 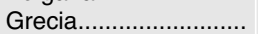 & 636 & 544 & nd & 540 & 448 & 373 & $-41,4$ \\
\hline 21 & 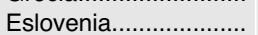 & 326 & 323 & 325 & 323 & 329 & 334 & 2,5 \\
\hline 22 & 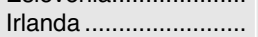 & 186 & 177 & 166 & 184 & 168 & 165 & $-11,3$ \\
\hline 23 & 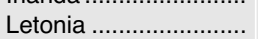 & 110 & 110 & 131 & 136 & 161 & 163 & 48,2 \\
\hline 24 & 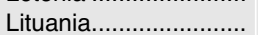 & 162 & 150 & 153 & 149 & 156 & 155 & $-4,3$ \\
\hline 25 & 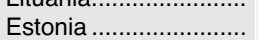 & 126 & 121 & 118 & 114 & 113 & 119 & $-5,6$ \\
\hline 26 & 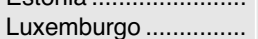 & 10 & 11 & 11 & 10 & 11 & 10 & 0,0 \\
\hline 27 & Malta & nd & nd & 33 & nd & nd & nd & nd \\
\hline 28 & 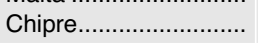 & 14 & 13 & nd & nd & nd & nd & nd \\
\hline \multicolumn{2}{|c|}{ Total } & 49.466 & 49.433 & 47.202 & 46.005 & 45.461 & 45.957 & $-7,1$ \\
\hline
\end{tabular}




\begin{tabular}{|c|c|c|c|c|c|c|c|c|}
\hline PORCEN & TAJE DE LAS EMPRES & EL SEC & $\begin{array}{l}\text { NUFAC1 } \\
\text { DE N }\end{array}$ & $\begin{array}{l}\text { DRO } 7 \\
\text { DE ALT } \\
\text { MENO }\end{array}$ & ${ }_{3}^{\text {LOGi }}$ & OTAL & OR M & TURE \\
\hline Ranking & País & 2008 & 2009 & 2010 & 2011 & 2012 & 2013 & $\begin{array}{c}\text { Var } \\
13 / 08 \\
(\mathrm{pp})\end{array}$ \\
\hline 1 & Reino Unido ................... & 5,7 & 5,8 & 5,5 & 5,4 & 5,1 & 5,1 & $-0,6$ \\
\hline 2 & Dinamarca........................... & 3,8 & 4,0 & 4,0 & 4,2 & 4,3 & 4,3 & 0,5 \\
\hline 3 & Alemania .......................... & 4,0 & 4,9 & 4,3 & 4,1 & 4,0 & 4,3 & 0,3 \\
\hline 4 & Irlanda & 3,7 & 4,0 & 4,0 & 4,1 & 4,2 & 4,1 & 0,3 \\
\hline 5 & Suecia .............................. & 3,6 & 3,6 & 3,4 & 3,4 & 3,3 & 3,3 & $-0,3$ \\
\hline 6 & Hungría ............................ & 4,8 & 3,3 & 3,4 & 3,3 & 3,2 & 3,3 & $-1,5$ \\
\hline 7 & Países Bajos ................... & 3,1 & 3,1 & 3,1 & 3,2 & 3,1 & 3,0 & $-0,1$ \\
\hline 8 & Croacia............................ & 3,5 & 3,5 & 3,3 & 3,4 & 3,3 & 2,8 & $-0,7$ \\
\hline 9 & 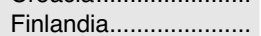 & 2,6 & 2,6 & 2,7 & 2,7 & 2,8 & 2,7 & 0,1 \\
\hline 10 & Austria …………… & 2,6 & 2,5 & 2,6 & 2,6 & 2,7 & 2,7 & 0,1 \\
\hline 11 & Rumania.......................... & 2,3 & 2,2 & 2,2 & 2,1 & 2,1 & 2,1 & $-0,2$ \\
\hline 12 & República Checa........ & 2,5 & 2,4 & 2,1 & 2,0 & 2,0 & 2,0 & $-0,4$ \\
\hline 13 & Polonia ............................. & 1,3 & 1,7 & 1,8 & 1,7 & 1,7 & 2,0 & 0,7 \\
\hline 14 & Estonia ........................... & 2,3 & 2,2 & 2,2 & 2,0 & 1,9 & 1,9 & $-0,4$ \\
\hline 15 & 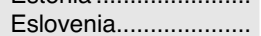 & 1,9 & 1,9 & 1,9 & 1,9 & 1,9 & 1,8 & 0,0 \\
\hline 16 & Bélgica .......................... & nd & 2,2 & nd & nd & 1,8 & 1,7 & nd \\
\hline 17 & Letonia .................. & 1,5 & 1,5 & 1,7 & 1,8 & 1,8 & 1,7 & 0,2 \\
\hline 18 & España ...................... & 1,6 & 1,6 & 1,6 & 1,6 & 1,6 & 1,6 & 0,0 \\
\hline 19 & Francia .................... & 2,1 & 2,1 & 1,6 & 1,5 & 1,5 & 1,5 & $-0,7$ \\
\hline 20 & Bulgaria ............................ & 1,5 & 1,4 & 1,4 & 1,4 & 1,4 & 1,5 & 0,0 \\
\hline 21 & Italia.............................. & 1,6 & 1,6 & 1,6 & 1,5 & 1,4 & 1,4 & $-0,2$ \\
\hline 22 & Eslovaquia......................... & 3,3 & nd & 1,2 & 1,2 & 1,1 & 1,2 & $-2,1$ \\
\hline 23 & Luxemburgo .................... & 1,2 & 1,3 & 1,3 & 1,2 & 1,3 & 1,2 & 0,0 \\
\hline 24 & Lituania............................... & 1,0 & 1,2 & 1,2 & 1,1 & 1,0 & 1,0 & $-0,1$ \\
\hline 25 & Portugal.......................... & 0,7 & 0,6 & 0,6 & 0,6 & 0,6 & 0,7 & 0,1 \\
\hline 26 & 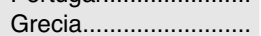 & 0,7 & 0,7 & nd & 0,7 & 0,7 & 0,6 & $-0,1$ \\
\hline 27 & Chipre.......................... & 0,3 & 0,2 & nd & nd & nd & nd & nd \\
\hline 28 & Malta ................................ & nd & nd & nd & nd & nd & nd & nd \\
\hline Total ....... & 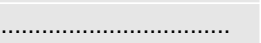 & 2,3 & 2,4 & 2,2 & 2,2 & 2,2 & 2,2 & $-0,1$ \\
\hline $\begin{array}{l}\text { pp: punto } \\
\text { nd: no dis } \\
\text { Fuente: }\end{array}$ & $\begin{array}{l}\text { porcentuales. } \\
\text { oonible. } \\
\text { urostat. Datos actuali }\end{array}$ & & & & & & & \\
\hline
\end{tabular}

de alta tecnología con 2.704 empresas, un 16,0 por 100 menos que en 2008. Lidera el ranking Alemania con 8.713 empresas, el 19,0 por 100 del total y un 11,8 por 100 más que en 2008 (Cuadro 6, en la página anterior).

En referencia al porcentaje de empresas manufactureras de alta tecnología sobre el total de empresas manufactureras, el ranking a nivel europeo lo lidera el Reino Unido con el 5,1 por 100 , superior al porcentaje de la UE en su conjunto (2,2 por 100). España se sitúa en el puesto número $18^{\circ}$ con el 1,6 por 100 , el mismo porcentaje que en 2008 (Cuadro 7).

\subsubsection{Empresas manufactureras de tecnología media-alta}

España era en 2013 el $6^{\circ}$ país de la UE con el mayor número de empresas manufactureras de tecnología media-alta con 12.665 empresas, un 22,4 por 100 menos que en 2008 (Cuadro 8). Nuevamente, el ranking lo lidera Alemania con 41.559 empresas, el 20,7 por 100 de total y un 4,0 por 100 menos que en 2008.

En referencia al porcentaje de empresas manufactureras de tecnología media-alta sobre el total de empresas manufactureras de cada país, el ranking a nivel europeo lo lidera Dinamarca con el 17,2 por 100, superior al porcentaje de la UE en su conjunto 9,7 por 100 . España se sitúa en el puesto número $17^{\circ}$ con el 7,5 por $100,0,4$ puntos porcentuales menos que en 2008 (Cuadro 9).

\section{Enfoque por productos}

El enfoque por productos permite explicar la situación competitiva y comercial de un país o sector en los mercados internacionales de alta tecnología. 


\section{LA EVOLUCIÓN DEL COMERCIO EXTERIOR ESPAÑOL DE ALTA TECNOLOGÍA}

\begin{tabular}{|c|c|c|c|c|c|c|c|c|}
\hline \multicolumn{9}{|c|}{$\begin{array}{l}\text { CUADRO } 8 \\
\text { UE. NÚMERO DE EMPRESAS DEL SECTOR MANUFACTURERO DE TECNOLOGÍA MEDIA-ALTA POR PAÍSES } \\
\text { DE MAYOR A MENOR EN } 2013\end{array}$} \\
\hline Ranking & País & 2008 & 2009 & 2010 & 2011 & 2012 & 2013 & Var. 13/08 \\
\hline 1 & Italia........................ & 43.290 & 43.148 & 43.357 & 43.575 & 42.056 & 41.559 & $-4,0$ \\
\hline 2 & Alemania .......................... & 28.282 & 27.023 & 29.893 & 29.567 & 29.107 & 29.567 & 4,5 \\
\hline 3 & República Checa.......... & 24.406 & 24.762 & 25.553 & 24.959 & 24.218 & 22.830 & $-6,5$ \\
\hline 4 & Reino Unido ...................... & 21.334 & 19.749 & 18.789 & 18.202 & 17.899 & 18.132 & $-15,0$ \\
\hline 5 & Francia ........................... & 16.599 & 14.131 & 13.883 & 13.510 & 13.173 & 13.273 & $-20,0$ \\
\hline 6 & España ………….... & 16.322 & 15.842 & 15.294 & 14.409 & 14.010 & 12.665 & $-22,4$ \\
\hline 7 & Polonia ........................... & 11.586 & 11.964 & 11.643 & 11.647 & 11.436 & 11.369 & $-1,9$ \\
\hline 8 & Países Bajos .................... & 6.209 & 6.599 & 7.123 & 7.092 & 7.055 & 7.475 & 20,4 \\
\hline 9 & Suecia & 7.044 & 7.021 & 7.000 & 7.041 & 7.015 & 6.917 & $-1,8$ \\
\hline 10 & 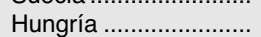 & 7.448 & 5.132 & 4.964 & 4.900 & 4.770 & 4.645 & $-37,6$ \\
\hline 11 & Portugal ..................... & 4.573 & 4.332 & 4.065 & 3.966 & 3.768 & 3.920 & $-14,3$ \\
\hline 12 & 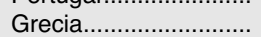 & 5.953 & 5.770 & nd & 5.330 & 4.389 & 3.678 & $-38,2$ \\
\hline 13 & Rumania ..................... & 4.130 & 4.019 & 3.766 & 3.528 & 3.539 & 3.602 & $-12,8$ \\
\hline 14 & Eslovaquia........................ & 1.219 & 1.363 & 3.800 & 3.652 & 3.512 & 3.445 & 182,6 \\
\hline 15 & 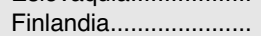 & 3.147 & 3.006 & 2.963 & 2.909 & 2.841 & 2.805 & $-10,9$ \\
\hline 16 & Bélgica ………… & nd & nd & 3.549 & 3.300 & 3.000 & 2.793 & nd \\
\hline 17 & Dinamarca ........................ & 2.705 & 2.661 & 2.656 & 2.652 & 2.658 & 2.590 & $-4,3$ \\
\hline 18 & Austria ……...................... & 2.581 & 2.490 & 2.509 & 2.524 & 2.529 & 2.536 & $-1,7$ \\
\hline 19 & 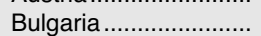 & 2.218 & 2.182 & 2.174 & 2.104 & 2.085 & 2.104 & $-5,1$ \\
\hline 20 & Croacia............................ & 2.234 & 2.312 & 2.138 & 2.035 & 1.992 & 1.965 & $-12,0$ \\
\hline 21 & 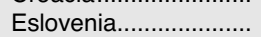 & 1.684 & 1.626 & 1.587 & 1.566 & 1.572 & 1.594 & $-5,3$ \\
\hline 22 & Letonia ........................... & 383 & 371 & 435 & 430 & 557 & 582 & 52,0 \\
\hline 23 & Lituania............................... & 440 & 422 & 409 & 421 & 474 & 502 & 14,1 \\
\hline 24 & Estonia .......................... & 421 & 403 & 409 & 411 & 450 & 483 & 14,7 \\
\hline 25 & Luxemburgo ....................... & 69 & 70 & 70 & 65 & 68 & 70 & 1,4 \\
\hline 26 & Irlanda & 690 & 616 & nd & nd & nd & nd & nd \\
\hline 27 & Chipre.................... & 315 & 314 & nd & nd & nd & nd & nd \\
\hline 28 & Malta & 132 & nd & nd & nd & nd & nd & nd \\
\hline \multicolumn{2}{|c|}{ 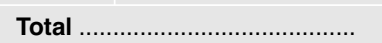 } & 215.414 & 207.328 & 208.029 & 209.795 & 204.173 & 201.101 & $-6,6$ \\
\hline
\end{tabular}

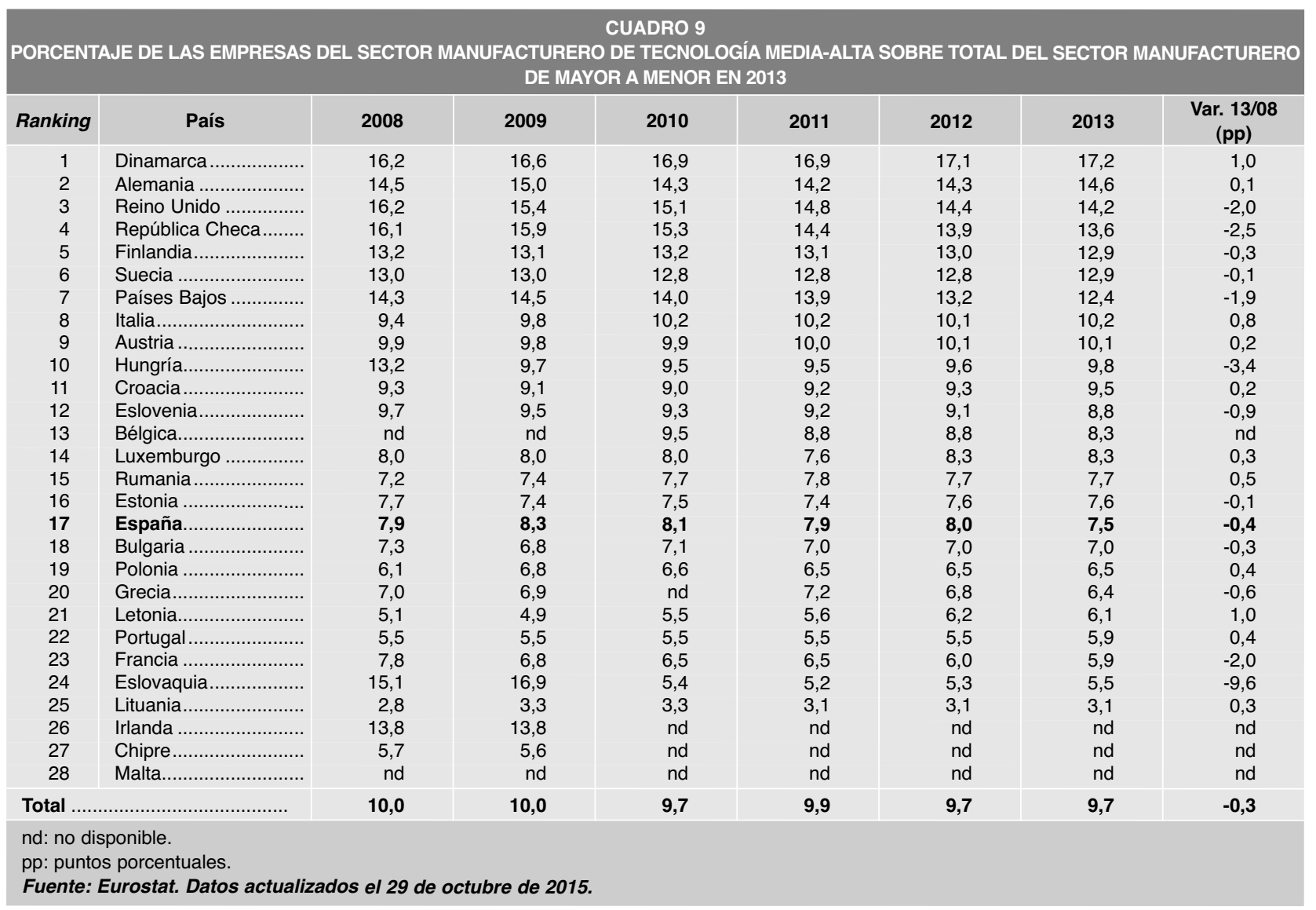


En 1994, la OCDE presentó una lista de productos de alta tecnología utilizando para ello la revisión 3 de la Clasificación Uniforme para el Comercio Internacional (CUCl). Esta lista era el resultado de cálculos referentes a las intensidades de I+D por grupo de productos (gastos en I+D/cifra de negocios). Actualmente se basa sobre la revisión 4 de la CUCl. Debido a la propia naturaleza del avance tecnológico, la definición de alta tecnología puede ir cambiando a lo largo del tiempo y con ella el listado de productos que incluye. Se puede consultar la lista de correspondencias utilizada por el INE en el Anexo 2.

\subsection{Datos de productos de alta tecnología de España}

Al igual que con el enfoque sectorial, los datos correspondientes a España provienen de los indicadores del sector de alta tecnología del INE. El análisis se centra en los 9 grupos de productos definidos, si bien se puede obtener una desagregación mayor en los indicadores publicados por el INE. En los Anexos 3 y 4 se han incluido estadísticas de exportaciones e importaciones españolas con una mayor desagregación. En el presente apartado, como análisis previo, se presentará la producción en España de los productos de alta tecnología, para posteriormente abordar el comercio exterior.

\subsubsection{Producción}

En 2014, la producción industrial española de productos de alta tecnología alcanzó los 8.358,4 millones de euros, el 2,2 por 100 del total de producción industrial. Este porcentaje se ha mantenido relativamente estable, si bien entre 2009 y 2011 se situó ligeramente por encima, alcanzando en 2009 el máximo de los últimos 7 años con el 2,5 por 100 (Cuadro 10).
Entre los productos de alta tecnología, en la actualidad, los de mayor peso son los productos farmacéuticos, representando una cuarta parte del total de la producción de alta tecnología (25,0 por 100), le sigue la producción de productos químicos $(18,2$ por 100) y de material electrónico, equipos y aparatos de radio, TV y comunicaciones (17,2 por 100). La producción de productos de alta tecnología ha caído en el periodo 2008-2014 un 12,8 por 100 , algo menos que la producción industrial en su conjunto (-13,8 por 100). Por grupos de productos, en el mismo periodo destaca el incremento del 60,6 por 100 de la construcción aeronáutica y espacial y del 16,5 por 100 la de productos farmacéuticos.

\subsubsection{Exportaciones}

En 2014, España exportó productos de alta tecnología por valor de 12.391,3 millones de euros, el 5,2 por 100 del total de la exportación española, un punto porcentual más que en 2008. Este porcentaje se ha mantenido relativamente estable entre 2009 y 2014, alrededor del 5,0 por 100 (Cuadro 11).

Las exportaciones de productos de alta tecnología con mayor peso en las exportaciones totales son los productos farmacéuticos con el 1,4 por 100 , les siguen los de construcción aeronáutica y espacial (1,0 por 100) y maquinaria de oficina y equipo informático $(0,8$ por 100).

En el periodo 2008-2014, las exportaciones de productos de alta tecnología se han incrementado un 56,3 por 100 hasta los 12.391,3 millones de euros, muy por encima del crecimiento de las exportaciones en su conjunto (27,1 por 100). En este periodo destaca el crecimiento del 140,1 por 100 de las exportaciones de productos farmacéuticos, del 98,8 por 100 en maquinaria y material eléctrico y del 73,6 por 100 en construcción aeronáutica y espacial. 


\begin{tabular}{|c|c|c|c|c|c|c|c|c|}
\hline \multicolumn{9}{|c|}{$\begin{array}{c}\text { CUADRO } 10 \\
\text { VALOR DE LA PRODUCCIÓN DE BIENES DE ALTA TECNOLOGÍA POR GRUPOS DE PRODUCTOS } \\
\text { (Millones de euros) }\end{array}$} \\
\hline Grupos de productos & 2008 & 2009 & 2010 & 2011 & 2012 & 2013 & 2014 & \begin{tabular}{|c|} 
Var. (\%) \\
2014/2008
\end{tabular} \\
\hline 1. Construcción aeronáutica y espacial ........................... & 560,6 & 617,2 & 594,3 & 568,1 & 573,0 & 565,0 & 900,3 & 60,6 \\
\hline 2. Maquinaria de oficina y eq. informático ..................... & 219,9 & 112,5 & 89,1 & 117,8 & 110,0 & 94,3 & 109,8 & $-50,1$ \\
\hline 3. Mat. electrónico, eq. y ap. radio, TV y comunic......... & $2.709,4$ & $2.222,5$ & $2.314,8$ & $1.996,8$ & $1.431,0$ & $1.336,5$ & $1.441,5$ & $-46,8$ \\
\hline 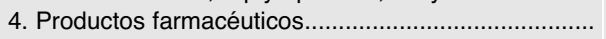 & $1.792,4$ & $1.814,5$ & $2.039,6$ & $2.087,4$ & $2.206,4$ & $2.146,3$ & $2.088,0$ & 16,5 \\
\hline 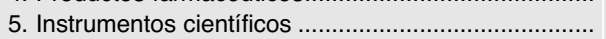 & 944,6 & 912,5 & 968,7 & 899,2 & 924,9 & 937,2 & 921,2 & $-2,5$ \\
\hline 6. Maquinaria y material eléctrico ............................... & 228,3 & 196,6 & 164,3 & 165,8 & 164,9 & 162,5 & 149,7 & $-34,4$ \\
\hline 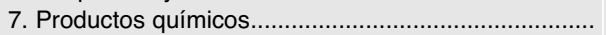 & $1.425,5$ & $1.190,3$ & $1.216,0$ & $1.600,0$ & $1.684,6$ & $1.560,8$ & $1.518,0$ & 6,5 \\
\hline 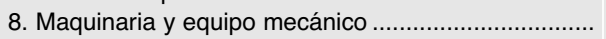 & 970,3 & 726,4 & 615,6 & 709,6 & 734,4 & 864,8 & 807,3 & $-16,8$ \\
\hline 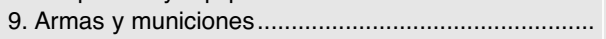 & 730,9 & 607,0 & 614,8 & 512,4 & 502,0 & 437,5 & 422,8 & $-42,2$ \\
\hline Total productos de alta tecnología.............................. & $9.581,8$ & $8.399,5$ & $8.617,2$ & $8.657,0$ & $8.331,3$ & $8.104,9$ & $8.358,4$ & $-12,8$ \\
\hline 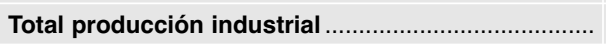 & 431.191,1 & $337.105,7$ & $359.825,7$ & $383.443,0$ & $377.949,1$ & $369.133,3$ & $371.771,9$ & $-13,8$ \\
\hline \multicolumn{9}{|c|}{ Porcentaje sobre el total de la producción de productos de alta tecnología } \\
\hline & 2008 & 2009 & 2010 & 2011 & 2012 & 2013 & 2014 & $\begin{array}{c}\text { Var. (pp) } \\
\text { 2014/2008 }\end{array}$ \\
\hline 1. Construcción aeronáutica y espacial ............................ & 5,9 & 7,3 & 6,9 & 6,6 & 6,9 & 7,0 & 10,8 & 4,9 \\
\hline 2. Maquinaria de oficina y eq. informático ....................... & 2,3 & 1,3 & 1,0 & 1,4 & 1,3 & 1,2 & 1,3 & $-1,0$ \\
\hline 3. Mat. electrónico, eq. y ap. radio, TV y comunic......... & 28,3 & 26,5 & 26,9 & 23,1 & 17,2 & 16,5 & 17,2 & $-11,0$ \\
\hline 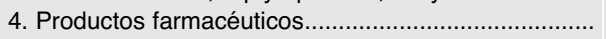 & 18,7 & 21,6 & 23,7 & 24,1 & 26,5 & 26,5 & 25,0 & 6,3 \\
\hline 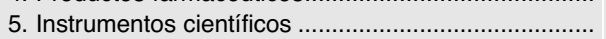 & 9,9 & 10,9 & 11,2 & 10,4 & 11,1 & 11,6 & 11,0 & 1,2 \\
\hline 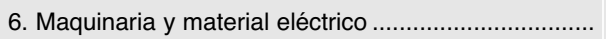 & 2,4 & 2,3 & 1,9 & 1,9 & 2,0 & 2,0 & 1,8 & $-0,6$ \\
\hline 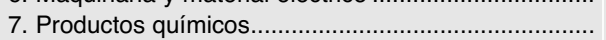 & 14,9 & 14,2 & 14,1 & 18,5 & 20,2 & 19,3 & 18,2 & 3,3 \\
\hline 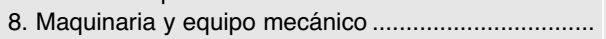 & 10,1 & 8,6 & 7,1 & 8,2 & 8,8 & 10,7 & 9,7 & $-0,5$ \\
\hline 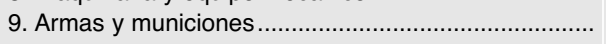 & 7,6 & 7,2 & 7,1 & 5,9 & 6,0 & 5,4 & 5,1 & $-2,6$ \\
\hline 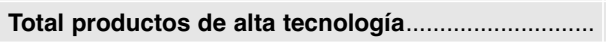 & 100,0 & 100,0 & 100,0 & 100,0 & 100,0 & 100,0 & 100,0 & - \\
\hline Producción alta tecnología sobre industrial (\%) & 2,2 & 2,5 & 2,4 & 2,3 & 2,2 & 2,2 & 2,2 & 0,0 \\
\hline
\end{tabular}

\begin{tabular}{|c|c|c|c|c|c|c|c|c|}
\hline \multicolumn{9}{|c|}{$\begin{array}{l}\text { CUADRO } 11 \\
\text { VALOR DE LAS EXPORTACIONES DE ALTA TECNOLOGÍA POR GRUPOS DE PRODUCTOS } \\
\text { (Millones de euros) }\end{array}$} \\
\hline Grupos de productos & 2008 & 2009 & 2010 & 2011 & 2012 & 2013 & 2014 & $\begin{array}{c}\text { Var. (\%) } \\
\text { 2014/2008 }\end{array}$ \\
\hline 1. Construcción aeronáutica y espacial ......................... & $1.359,2$ & $1.397,2$ & $1.464,9$ & $1.786,4$ & $1.960,5$ & $3.770,6$ & $2.360,2$ & 73,6 \\
\hline 2. Maquinaria de oficina y eq. informático ..................... & 596,4 & 641,7 & 665,3 & 681,9 & 654,1 & 693,3 & 705,7 & 18,3 \\
\hline 3. Mat. electrónico, eq. y ap. radio, TV y comunic........ & $1.677,5$ & $1.784,5$ & $2.575,3$ & $2.285,9$ & $1.892,7$ & $1.711,8$ & $1.928,1$ & 14,9 \\
\hline 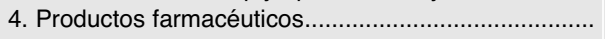 & $1.367,4$ & $1.484,5$ & $1.682,8$ & $2.107,2$ & $3.121,1$ & $2.722,6$ & $3.283,6$ & 140,1 \\
\hline 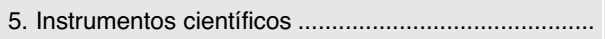 & 737,1 & 634,4 & 761,3 & 855,5 & 999,4 & 933,8 & $1.186,6$ & 61,0 \\
\hline 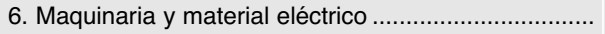 & 166,1 & 139,6 & 174,8 & 266,2 & 244,1 & 310,7 & 330,2 & 98,8 \\
\hline 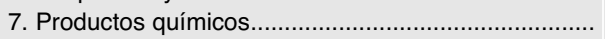 & $1.022,3$ & 758,3 & 992,7 & $1.292,2$ & $1.494,5$ & $1.424,4$ & $1.505,2$ & 47,2 \\
\hline 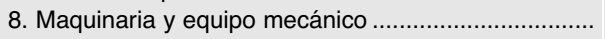 & 850,8 & 777,0 & 652,2 & $1.071,3$ & 921,5 & $1.125,5$ & 916,3 & 7,7 \\
\hline 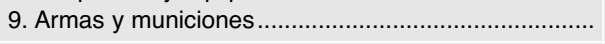 & 152,4 & 173,0 & 174,8 & 93,8 & 119,4 & 181,0 & 175,3 & 15,0 \\
\hline Total exportaciones de alta tecnología ......................... & $7.929,2$ & $7.790,4$ & $9.144,2$ & $10.440,4$ & $11.407,4$ & $12.873,6$ & $12.391,3$ & 56,3 \\
\hline 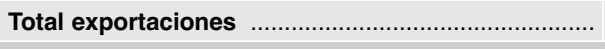 & $189.227,9$ & $159.889,6$ & $186.780,1$ & $215.230,4$ & $226.114,6$ & $235.814,1$ & $240.581,8$ & 27,1 \\
\hline \multicolumn{9}{|c|}{ Porcentaje sobre el total de las exportaciones } \\
\hline & 2008 & 2009 & 2010 & 2011 & 2012 & 2013 & 2014 & $\begin{array}{c}\text { Var. (pp) } \\
\text { 2014/2008 }\end{array}$ \\
\hline 1. Construcción aeronáutica y espacial ......................... & 0,7 & 0,9 & 0,8 & 0,8 & 0,9 & 1,6 & 1,0 & 0,3 \\
\hline 2. Maquinaria de oficina y eq. informático ....................... & 0,3 & 0,4 & 0,4 & 0,3 & 0,3 & 0,3 & 0,3 & 0,0 \\
\hline 3. Mat. electrónico, eq. y ap. radio, TV y comunic........ & 0,9 & 1,1 & 1,4 & 1,1 & 0,8 & 0,7 & 0,8 & $-0,1$ \\
\hline 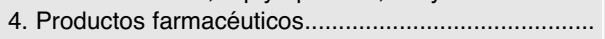 & 0,7 & 0,9 & 0,9 & 1,0 & 1,4 & 1,2 & 1,4 & 0,6 \\
\hline 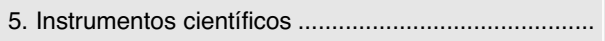 & 0,4 & 0,4 & 0,4 & 0,4 & 0,4 & 0,4 & 0,5 & 0,1 \\
\hline 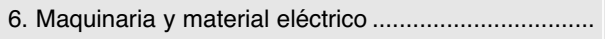 & 0,1 & 0,1 & 0,1 & 0,1 & 0,1 & 0,1 & 0,1 & 0,0 \\
\hline 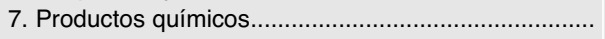 & 0,5 & 0,5 & 0,5 & 0,6 & 0,7 & 0,6 & 0,6 & 0,1 \\
\hline 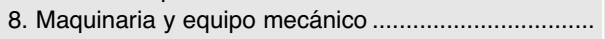 & 0,4 & 0,5 & 0,3 & 0,5 & 0,4 & 0,5 & 0,4 & $-0,1$ \\
\hline 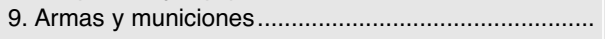 & 0,1 & 0,1 & 0,1 & 0,0 & 0,1 & 0,1 & 0,1 & 0,0 \\
\hline Total exportaciones de alta tecnología ....................... & 4,2 & 4,9 & 4,9 & 4,9 & 5,0 & 5,5 & 5,2 & 1,0 \\
\hline
\end{tabular}




\begin{tabular}{|c|c|c|c|c|c|c|c|c|}
\hline \multicolumn{9}{|c|}{$\begin{array}{l}\text { CUADRO } 12 \\
\text { EXPORTACIONES SOBRE LA PRODUCCIÓN INDUSTRIAL DE ALTA TECNOLOGÍA POR GRUPOS DE PRODUCTOS } \\
\text { (En porcentaje) }\end{array}$} \\
\hline Grupos de productos & 2008 & 2009 & 2010 & 2011 & 2012 & 2013 & 2014 & $\begin{array}{c}\text { Var. 2014/2008 } \\
(p p)\end{array}$ \\
\hline 1. Construcción aeronáutica y espacial ........................... & 242,5 & 226,4 & 246,5 & 314,5 & 342,1 & 667,4 & 262,2 & 8,1 \\
\hline 2. Maquinaria de oficina y eq. informático ...................... & 271,2 & 570,4 & 746,7 & 578,9 & 594,6 & 735,2 & 642,7 & 137,0 \\
\hline 3. Mat. electrónico, eq. y ap. radio, TV y comunic. ... & 61,9 & 80,3 & 111,3 & 114,5 & 132,3 & 128,1 & 133,8 & 116,0 \\
\hline 4. Productos farmacéuticos & 76,3 & 81,8 & 82,5 & 100,9 & 141,5 & 126,9 & 157,3 & 106,1 \\
\hline 5. Instrumentos científicos & 78,0 & 69,5 & 78,6 & 95,1 & 108,1 & 99,6 & 128,8 & 65,1 \\
\hline 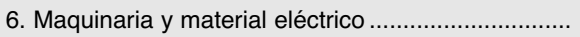 & 72,8 & 71,0 & 106,4 & 160,6 & 148,0 & 191,2 & 220,6 & 203,2 \\
\hline 7. Productos químicos & 71,7 & 63,7 & 81,6 & 80,8 & 88,7 & 91,3 & 99,2 & 38,3 \\
\hline 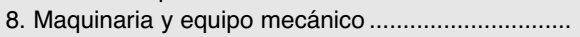 & 87,7 & 107,0 & 105,9 & 151,0 & 125,5 & 130,1 & 113,5 & 29,4 \\
\hline 9. Armas y municiones & 20,9 & 28,5 & 28,4 & 18,3 & 23,8 & 41,4 & 41,5 & 98,8 \\
\hline Total alta tecnología & 82,8 & 92,7 & 106,1 & 120,6 & 136,9 & 158,8 & 148,2 & 79,1 \\
\hline
\end{tabular}

Los productos de alta tecnología están mejor representados en las exportaciones con el 5,2 por 100 del total de las exportaciones en 2014, que en el total de la producción industrial $(2,2$ por 100$)$.

\subsubsection{Exportaciones sobre la producción industrial de productos de alta tecnología}

En 2014, las exportaciones de productos de alta tecnología supusieron el 148,2 por 100 de la producción de este tipo de productos. Este hecho puede indicar que se están exportando desde España productos de alta tecnología producidos en el extranjero. La mayor ratio entre exportaciones y producción ocurre en la maquinaria de oficina y equipo informático, que alcanzó en 2014 el 642,7 por 100. En cambio la menor ratio correspondió a armas y municiones con el 41,5 por 100 (Cuadro 12).

\subsubsection{Importaciones}

En 2014, España importó productos de alta tecnología por valor de 21.457,3 millones de euros, el 8,1 por 100 de las importaciones totales, casi dos puntos por debajo del valor que representaban en el año 2008 (Cuadro 13). Aunque este porcentaje es superior al equivalente de las exportaciones del 5,2 por 100, la brecha entre estas ratios se ha ido reduciendo desde los 5,8 puntos porcentuales en 2008 a los 2,9 puntos del año 2014 .
Las importaciones de productos de alta tecnología con mayor peso en las importaciones totales son las de material electrónico, equipos y aparatos de radio, TV y comunicaciones, con el 2,7 por 100 de la importación total. Les siguen las de maquinaria de oficina y equipo informático con el 1,4 por 100 y las de productos farmacéuticos con el 1,3 por 100 .

En el periodo 2008-2014, las importaciones de productos de alta tecnología se han reducido un 24,4 por 100 hasta los $21.457,3$ millones de euros, caída de mayor calado que en las del conjunto de las importaciones (-6,3 por 100). En el periodo 2008-2014 destaca la caída del 44,0 por 100 de las importaciones de material electrónico, equipos y aparatos de radio, que se reducen desde los 13.002,0 millones de euros en 2008 a los 7.279,0 millones en 2014. Otras caídas de los sectores con mayor peso han sido las de construcción aeronáutica y espacial (-32,9 por 100) y de maquinaria de oficina y equipo informático (-23,5 por 100). En el extremo opuesto está el fuerte crecimiento de la importación de instrumentos científicos $(14,5$ por 100$)$ y de productos farmacéuticos (8,3 por 100).

\subsubsection{Tasa de cobertura}

En 2014, la tasa de cobertura de España (cociente de las exportaciones sobre las importaciones en porcentaje) alcanzó el 90,6 por $100 \triangleright$ 


\section{LA EVOLUCIÓN DEL COMERCIO EXTERIOR ESPAÑOL DE ALTA TECNOLOGÍA}

\begin{tabular}{|l|r|r|r|r|r|r|r|r|}
\multicolumn{7}{c}{ CUADRO 13} \\
VALOR DE LAS IMPORTACIONES DE PRODUCTOS DE ALTA TECNOLOGÍA POR GRUPOS DE PRODUCTOS \\
(Millones de euros)
\end{tabular}

pp: puntos porcentuales.

Fuente: INE, Indicadores de Alta Tecnología (a partir de datos del Departamento de Aduanas e IIEE de la AEAT).

\begin{tabular}{|c|c|c|c|c|c|c|c|c|}
\hline TASA DE COBERTURA DEL COMERCIO E & ERIO & $\begin{array}{l}\text { CUAD } \\
\text { PROD } \\
\text { (En por }\end{array}$ & $\begin{array}{l}14 \\
\text { OS DE } \\
\text { taje) }\end{array}$ & A TEC & DGí & GRU & DE $F$ & TOS \\
\hline Grupos de productos & 2008 & 2009 & 2010 & 2011 & 2012 & 2013 & 2014 & $\begin{array}{c}\text { Var. (pp) } \\
2014 / 2008\end{array}$ \\
\hline 1. Construcción aeronáutica y espacial ...................... & 64,3 & 129,1 & 88,5 & 123,3 & 113,7 & 201,2 & 166,4 & 102,1 \\
\hline 2. Maquinaria de oficina y eq. informático .................. & 12,7 & 17,2 & 16,0 & 19,9 & 18,8 & 19,9 & 19,6 & 6,9 \\
\hline 3. Mat. electrónico, eq. y ap. radio, TV y comunic. ... & 12,9 & 27,2 & 30,8 & 28,9 & 28,0 & 26,1 & 26,5 & 13,6 \\
\hline 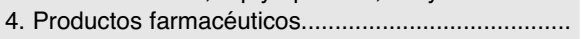 & 43,2 & 39,0 & 50,3 & 59,6 & 95,1 & 92,5 & 95,8 & 52,6 \\
\hline 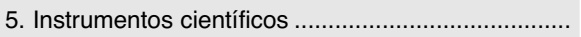 & 29,6 & 28,0 & 30,9 & 33,8 & 42,2 & 38,4 & 41,7 & 12,0 \\
\hline 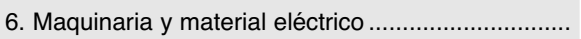 & 22,9 & 26,0 & 29,5 & 47,3 & 40,4 & 40,9 & 37,8 & 14,9 \\
\hline 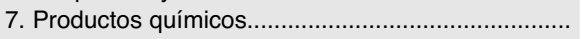 & 75,3 & 57,9 & 67,2 & 84,4 & 98,3 & 96,7 & 100,5 & 25,3 \\
\hline 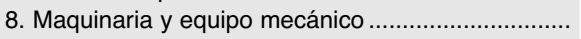 & 127,5 & 173,8 & 143,2 & 228,9 & 160,8 & 277,1 & 207,0 & 79,6 \\
\hline 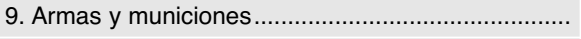 & 93,6 & 112,1 & 96,4 & 63,0 & 140,6 & 211,9 & 231,0 & 137,4 \\
\hline 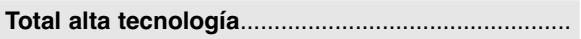 & 27,9 & 39,1 & 40,3 & 48,4 & 56,0 & 64,3 & 57,7 & 29,8 \\
\hline 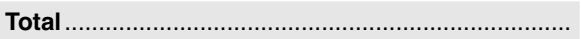 & 66,8 & 77,6 & 77,8 & 81,8 & 87,7 & 93,4 & 90,6 & 23,8 \\
\hline
\end{tabular}

para el conjunto del comercio exterior de bienes, claramente superior a la correspondiente a los productos de alta tecnología que registró el 57,7 por 100 . No obstante, la tasa de este tipo de productos ha evolucionado de manera muy favorable, habiéndose incrementado en prácticamente 30 puntos porcentuales desde el 27,9 por 100 registrada en 2008 (Cuadro 14).

Por productos, las mayores tasas de cobertura correspondieron a armas y municiones
(231,0 por 100) y maquinaria y equipo mecánico $(207,0$ por 100$)$. En el extremo opuesto se situaron maquinaria de oficina y equipo informático $(19,6$ por 100) y material electrónico equipos y aparatos de radio, TV y comunicaciones (26,5 por 100$)$.

En el periodo 2008-2014 ha mejorado la tasa de cobertura en España para todos los grupos de productos. Entre los sectores con mayor volumen de comercio, destaca el fuerte $\triangle$ 
crecimiento de la tasa de cobertura de la construcción aeronáutica y espacial, que pasa del 64,3 por 100 en 2008 a 166,4 por 100 en 2014, así como la de productos farmacéuticos, que crece desde el 43,2 por 100 en 2008 al 95,8 por 100 en 2014.

\subsection{Datos comparativos de la Unión Europea}

\subsubsection{Exportaciones totales}

Con los datos de Eurostat, España fue en 2015 el séptimo principal exportador de la UE con 255.441 millones de euros, el 5,3 por 100 de las exportaciones de la UE, 0,5 puntos porcentuales más que en 2008. Lidera el ranking Alemania con casi un cuarto de las exportaciones $(24,7$ por 100), seguida de lejos por los Países Bajos con el 10,5 por 100. En el periodo 2008-2015, las exportaciones españolas han aumentado un 33,5 por 100 , por encima de las de la UE en su conjunto $(20,1$ por 100$)$, siendo la mayor tasa de entre las cinco principales economías de la UE (Cuadro 15).

\subsubsection{Exportaciones de productos de alta tecnología}

En 2015, España fue el $12^{\circ}$ exportador de productos de alta tecnología de la UE con 13.683 millones de euros, avanzando dos posiciones con respecto a 2008, aunque se sitúa cinco posiciones por debajo de la registrada para las exportaciones en su conjunto. En el periodo 2008-2015 las exportaciones de este tipo de productos han aumentado un 71,8 por 100 , por encima del incremento de la UE en su conjunto $(38,3$ por 100$)$, y resulta la mayor tasa de entre sus cinco principales economías (Cuadro 16).

Asimismo, las exportaciones españolas de alta tecnología representaron el 2,0 por 100 de las exportaciones de estos productos del conjunto de la UE, lejos del 26,1 por 100 que representaron las de Alemania o del 15,1 por 100 de los Países Bajos, aunque ha aumentado su peso en 0,4 puntos porcentuales con respecto al año 2008.

\subsubsection{Exportaciones de productos de alta tecnología sobre exportaciones totales}

A fin de hacer comparaciones en términos relativos, se ha calculado la ratio de las exportaciones de productos de alta tecnología sobre las exportaciones totales de cada país. En 2015 , las exportaciones españolas de alta tecnología representaron el 5,4 por 100 de las exportaciones totales españolas, lejos del 24,2 por 100 que representaron en Alemania o del 14,0 por 100 en el conjunto de la UE. No obstante, en España la ratio se ha incrementado en 1,2 puntos porcentuales con respecto al 4,2 por 100 registrado en el año 2008, mientras que en Alemania han perdido peso desde 38,3 por 100 desde ese mismo año. Con respecto a esta ratio, España se situó en el puesto 25 de la UE, tan solo por delante de Bulgaria, Grecia y Portugal (Cuadro 17).

\subsubsection{Importaciones totales}

España fue en 2015 el séptimo principal importador de la UE con 281.298 millones de euros, repitiendo posición con respecto a las exportaciones, y representaron el 6,0 por 100 de las importaciones de la UE en su conjunto, 0,8 puntos porcentuales menos que en 2008 . Lidera el ranking Alemania con una quinta parte de las importaciones (20,1 por 100$)$, seguida de lejos por el Reino Unido con el 12,0 por 100 y Francia con el 11,0 por 100 . En el periodo 2008-2015, las importaciones españolas se han reducido un 1,7 por 100, lo que contrasta con la subida del 10,7 por 100 de las de la UE en su conjunto, y de las cinco principales $\square$ 


\section{LA EVOLUCIÓN DEL COMERCIO EXTERIOR ESPAÑOL DE ALTA TECNOLOGÍA}

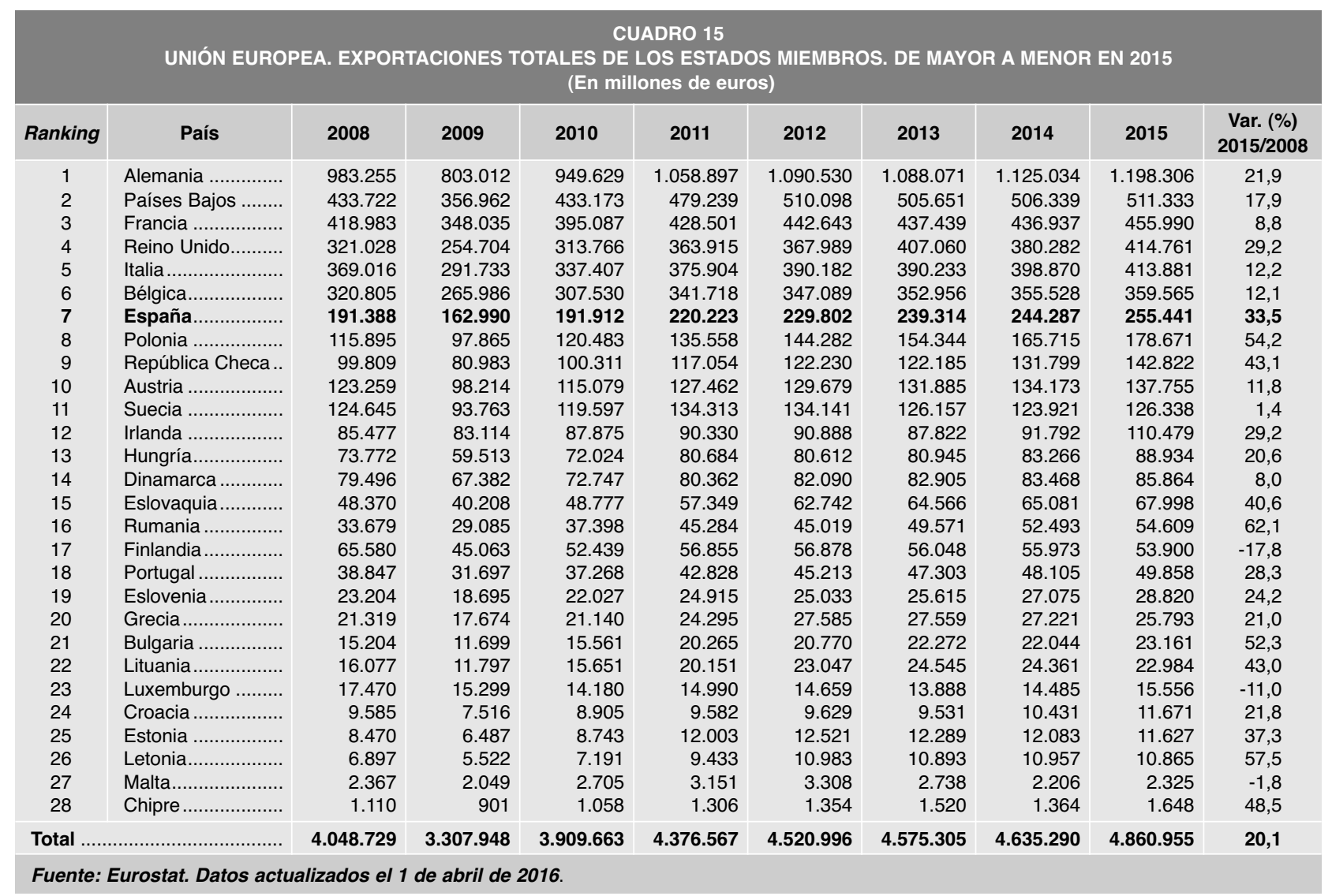

\begin{tabular}{|c|c|c|c|c|c|c|c|c|c|c|}
\hline & UE. EXPORTAC & IONES DE & RODUCTC & $\begin{array}{l}\text { DE ALTA } 7 \\
\text { (En mi }\end{array}$ & $\begin{array}{l}\text { ADRO } 16 \\
\text { PNOLOGí } \\
\text { nes de eu }\end{array}$ & E LOS EE & И. DE MA & A MENC & N 2015 & \\
\hline Ranking & País & 2008 & 2009 & 2010 & 2011 & 2012 & 2013 & 2014 & 2015 & $\begin{array}{c}\text { Var. (\%) } \\
\text { 2015/2008 }\end{array}$ \\
\hline 1 & Alemania ................. & 122.304 & 112.641 & 133.195 & 142.503 & 155.222 & 155.251 & 160.429 & 176.963 & 44,7 \\
\hline 2 & Países Bajos ......... & 70.089 & 65.621 & 80.538 & 82.324 & 95.779 & 89.559 & 94.330 & 102.168 & 45,8 \\
\hline 3 & Francia .................. & 73.621 & 68.681 & 80.611 & 80.010 & 88.614 & 89.223 & 90.637 & 98.446 & 33,7 \\
\hline 4 & Reino Unido............ & 49.585 & 48.511 & 55.481 & 59.703 & 64.106 & 62.941 & 59.377 & 69.322 & 39,8 \\
\hline 5 & Bélgica...................... & 21.801 & 23.362 & 25.840 & 26.256 & 29.724 & 30.740 & 34.725 & 36.966 & 69,6 \\
\hline 6 & Italia ............................... & 21.936 & 19.849 & 22.091 & 24.224 & 24.800 & 25.929 & 26.759 & 28.442 & 29,7 \\
\hline 7 & Irlanda ..................... & 20.756 & 18.351 & 16.642 & 18.296 & 18.807 & 18.368 & 19.567 & 26.617 & 28,2 \\
\hline 8 & República Checa.. & 14.115 & 12.331 & 16.123 & 19.193 & 19.665 & 18.431 & 20.168 & 22.030 & 56,1 \\
\hline 9 & Austria .................... & 13.358 & 11.509 & 13.620 & 14.272 & 16.594 & 18.786 & 19.270 & 19.507 & 46,0 \\
\hline 10 & 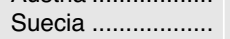 & 16.463 & 13.730 & 17.322 & 18.533 & 17.236 & 16.463 & 16.004 & 17.072 & 3,7 \\
\hline 11 & Polonia ..................... & 4.950 & 5.585 & 7.289 & 6.963 & 8.594 & 10.274 & 13.122 & 15.250 & 208,1 \\
\hline 12 & España.................. & 7.966 & 7.793 & 9.119 & 10.583 & 11.447 & 13.025 & 12.606 & 13.683 & 71,8 \\
\hline 13 & Hungría................... & 14.928 & 13.235 & 15.668 & 16.861 & 13.959 & 13.205 & 12.088 & 13.511 & $-9,5$ \\
\hline 14 & Dinamarca .............. & 8.515 & 8.315 & 6.762 & 7.442 & 7.748 & 7.723 & 8.238 & 9.161 & 7,6 \\
\hline 15 & Eslovaquia ............. & 2.516 & 2.358 & 3.216 & 3.779 & 5.164 & 6.230 & 6.436 & 6.647 & 164,2 \\
\hline 16 & Rumania ................. & 1.819 & 2.389 & 3.670 & 3.992 & 2.838 & 2.766 & 3.376 & 4.000 & 119,9 \\
\hline 17 & Finlandia ................. & 11.365 & 6.250 & 5.241 & 4.538 & 4.165 & 3.464 & 3.731 & 3.786 & $-66,7$ \\
\hline 18 & Luxemburgo ........... & 6.220 & 6.413 & 4.354 & 3.863 & 3.974 & 3.037 & 2.818 & 3.063 & $-50,8$ \\
\hline 19 & Portugal .................. & 2.467 & 1.159 & 1.130 & 1.314 & 1.492 & 1.609 & 1.739 & 1.885 & $-23,6$ \\
\hline 20 & 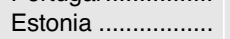 & 638 & 450 & 912 & 1.780 & 1.769 & 1.835 & 1.968 & 1.795 & 181,3 \\
\hline 21 & Lituania .................... & 1.048 & 689 & 945 & 1.136 & 1.333 & 1.435 & 1.596 & 1.730 & 65,1 \\
\hline 22 & Eslovenia .............. & 1.205 & 1.033 & 1.167 & 1.322 & 1.303 & 1.405 & 1.449 & 1.695 & 40,7 \\
\hline 23 & 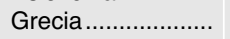 & 1.061 & 979 & 975 & 1.007 & 885 & 715 & 1.002 & 1.195 & 12,6 \\
\hline 24 & Bulgaria .................... & nd & nd & nd & nd & 794 & nd & 869 & 1.069 & nd \\
\hline 25 & Letonia .................... & 319 & 294 & 344 & 633 & 706 & 876 & 1.057 & 1.065 & 233,9 \\
\hline 26 & Croacia .................... & 640 & 570 & 619 & 559 & 691 & 750 & 686 & 824 & 28,8 \\
\hline 27 & Malta ........................ & 906 & 722 & 891 & 948 & 980 & 784 & 633 & 563 & $-37,9$ \\
\hline 28 & Chipre ..................... & 212 & 181 & 205 & 194 & 159 & 276 & 124 & 322 & 51,9 \\
\hline \multicolumn{2}{|l|}{ Total } & 490.803 & 453.001 & 523.970 & 552.228 & 598.548 & 595.100 & 614.804 & 678.777 & 38,3 \\
\hline
\end{tabular}




\begin{tabular}{|c|c|c|c|c|c|c|c|c|c|c|}
\hline \multicolumn{11}{|c|}{$\begin{array}{l}\text { CUADRO } 17 \\
\text { UE. EXPORTACIONES DE PROD. DE ALTA TECNOLOGÍA S. EXPORTACIONES TOTALES DE CADA EM, DE MAYOR A MENOR EN } 2015 \\
\text { (En porcentaje) }\end{array}$} \\
\hline Ranking & País & 2008 & 2009 & 2010 & 2011 & 2012 & 2013 & 2014 & 2015 & $\begin{array}{c}\text { Var. (pp) } \\
2015 / 2008\end{array}$ \\
\hline 1 & Malta........................... & 38,3 & 35,2 & 32,9 & 30,1 & 29,6 & 28,6 & 28,7 & 24,2 & $-14,1$ \\
\hline 2 & Irlanda ....................... & 24,3 & 22,1 & 18,9 & 20,3 & 20,7 & 20,9 & 21,3 & 24,0 & $-0,3$ \\
\hline 3 & 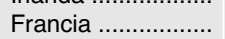 & 17,6 & 19,7 & 20,4 & 18,7 & 20,0 & 20,4 & 20,7 & 21,6 & 4,0 \\
\hline 4 & Países Bajos ......... & 16,2 & 18,4 & 18,6 & 17,2 & 18,8 & 17,7 & 18,6 & 20,0 & 3,8 \\
\hline 5 & Luxemburgo ........... & 35,6 & 41,9 & 30,7 & 25,8 & 27,1 & 21,9 & 19,5 & 19,7 & $-15,9$ \\
\hline 6 & 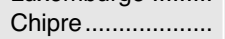 & 19,1 & 20,1 & 19,3 & 14,8 & 11,7 & 18,1 & 9,1 & 19,3 & 0,2 \\
\hline 7 & 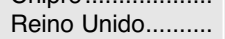 & 15,4 & 19,0 & 17,7 & 16,4 & 17,4 & 15,5 & 15,6 & 16,7 & 1,3 \\
\hline 8 & República Checa.. & 14,1 & 15,2 & 16,1 & 16,4 & 16,1 & 15,1 & 15,3 & 15,4 & 1,3 \\
\hline 9 & Estonia .................. & 7,5 & 6,9 & 10,4 & 14,8 & 14,1 & 14,9 & 16,3 & 15,4 & 7,9 \\
\hline 10 & Hungría.................... & 20,2 & 22,2 & 21,8 & 20,9 & 17,3 & 16,3 & 14,5 & 15,2 & $-5,0$ \\
\hline 11 & Alemania ................ & 12,4 & 14,0 & 14,0 & 13,5 & 14,2 & 14,3 & 14,3 & 14,8 & 2,4 \\
\hline 12 & Austria ....................... & 10,8 & 11,7 & 11,8 & 11,2 & 12,8 & 14,2 & 14,4 & 14,2 & 3,4 \\
\hline 13 & 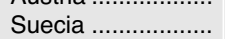 & 13,2 & 14,6 & 14,5 & 13,8 & 12,8 & 13,0 & 12,9 & 13,5 & 0,3 \\
\hline 14 & Dinamarca ............. & 10,7 & 12,3 & 9,3 & 9,3 & 9,4 & 9,3 & 9,9 & 10,7 & 0,0 \\
\hline 15 & Bélgica.................... & 6,8 & 8,8 & 8,4 & 7,7 & 8,6 & 8,7 & 9,8 & 10,3 & 3,5 \\
\hline 16 & Letonia.................... & 4,6 & 5,3 & 4,8 & 6,7 & 6,4 & 8,0 & 9,7 & 9,8 & 5,2 \\
\hline 17 & 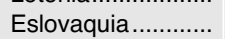 & 5,2 & 5,9 & 6,6 & 6,6 & 8,2 & 9,6 & 9,9 & 9,8 & 4,6 \\
\hline 18 & Polonia ................... & 4,3 & 5,7 & 6,0 & 5,1 & 6,0 & 6,7 & 7,9 & 8,5 & 4,2 \\
\hline 19 & Lituania ................... & 6,5 & 5,8 & 6,0 & 5,6 & 5,8 & 5,8 & 6,6 & 7,5 & 1,0 \\
\hline 20 & Rumania .................. & 5,4 & 8,2 & 9,8 & 8,8 & 6,3 & 5,6 & 6,4 & 7,3 & 1,9 \\
\hline 21 & Croacia .................... & 6,7 & 7,6 & 7,0 & 5,8 & 7,2 & 7,9 & 6,6 & 7,1 & 0,4 \\
\hline 22 & 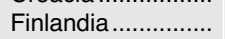 & 17,3 & 13,9 & 10,0 & 8,0 & 7,3 & 6,2 & 6,7 & 7,0 & $-10,3$ \\
\hline 23 & Italia ................................ & 5,9 & 6,8 & 6,5 & 6,4 & 6,4 & 6,6 & 6,7 & 6,9 & 1,0 \\
\hline 24 & Eslovenia ............... & 5,2 & 5,5 & 5,3 & 5,3 & 5,2 & 5,5 & 5,4 & 5,9 & nd \\
\hline 25 & España...................... & 4,2 & 4,8 & 4,8 & 4,8 & 5,0 & 5,4 & 5,2 & 5,4 & 1,2 \\
\hline 26 & Bulgaria ..................... & nd & nd & nd & nd & 3,8 & nd & 3,9 & 4,6 & nd \\
\hline 27 & Grecia ..................... & 5,0 & 5,5 & 4,6 & 4,1 & 3,2 & 2,6 & 3,7 & 4,6 & $-0,4$ \\
\hline 28 & Portugal ................... & 6,3 & 3,7 & 3,0 & 3,1 & 3,3 & 3,4 & 3,6 & 3,8 & $-2,5$ \\
\hline \multicolumn{2}{|c|}{ Total } & 12,1 & 13,7 & 13,4 & 12,6 & 13,2 & 13,0 & 13,3 & 14,0 & 1,8 \\
\hline \multicolumn{11}{|c|}{$\begin{array}{l}\text { nd: no disponible. } \\
\text { pp: puntos porcentuales. } \\
\text { Fuente: Eurostat. }\end{array}$} \\
\hline
\end{tabular}

\begin{tabular}{|c|c|c|c|c|c|c|c|c|c|c|}
\hline \multirow[b]{2}{*}{ Ranking } & \multicolumn{9}{|c|}{$\begin{array}{l}\text { CUADRO } 18 \\
\text { UNIÓN EUROPEA. IMPORTACIONES TOTALES DE LOS EEMM, DE MAYOR A MENOR EN } 2015 \\
\text { (En millones de euros) }\end{array}$} & \multirow[b]{2}{*}{$\begin{array}{c}\text { Var. (\%) } \\
2015 / 2008\end{array}$} \\
\hline & País & 2008 & 2009 & 2010 & 2011 & 2012 & 2013 & 2014 & 2015 & \\
\hline 1 & Alemania ......... & 805.730 & 664.143 & 795.666 & 901.487 & 898.857 & 889.416 & 908.575 & 946.454 & 17,5 \\
\hline 2 & Reino Unido............ & 447.228 & 372.581 & 445.291 & 487.905 & 541.112 & 496.977 & 519.733 & 564.190 & 26,2 \\
\hline 3 & Francia ................... & 487.350 & 404.098 & 460.941 & 517.262 & 524.918 & 513.114 & 509.299 & 515.938 & 5,9 \\
\hline 4 & Países Bajos ......... & 394.980 & 317.718 & 386.834 & 426.987 & 456.824 & 444.015 & 443.689 & 456.370 & 15,5 \\
\hline 5 & 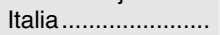 & 382.050 & 297.609 & 367.390 & 401.428 & 380.292 & 361.002 & 356.939 & 368.715 & $-3,5$ \\
\hline 6 & Bélgica..................... & 317.043 & 254.367 & 295.072 & 335.447 & 341.787 & 340.093 & 342.215 & 338.750 & 6,8 \\
\hline 7 & España.................. & 286.105 & 210.222 & 246.674 & 270.550 & 262.561 & 256.455 & 270.173 & 281.298 & $-1,7$ \\
\hline 8 & Polonia ................... & 141.966 & 107.155 & 134.306 & 151.291 & 154.934 & 156.319 & 168.366 & 174.990 & 23,3 \\
\hline 9 & Austria ...................... & 125.301 & 102.569 & 119.943 & 137.513 & 138.942 & 138.000 & 137.001 & 140.132 & 11,8 \\
\hline 10 & República Checa.. & 96.572 & 75.314 & 95.536 & 109.285 & 110.066 & 108.621 & 116.203 & 126.805 & 31,3 \\
\hline 11 & Suecia .................... & 114.565 & 85.945 & 112.352 & 127.174 & 127.985 & 120.931 & 122.132 & 124.467 & 8,6 \\
\hline 12 & Hungría................... & 74.069 & 55.750 & 66.514 & 73.592 & 74.078 & 75.379 & 78.978 & 83.487 & 12,7 \\
\hline 13 & Dinamarca .............. & 74.356 & 59.602 & 62.648 & 68.724 & 71.548 & 72.728 & 74.783 & 76.957 & 3,5 \\
\hline 14 & Irlanda ...................... & 57.088 & 44.955 & 45.467 & 47.849 & 48.855 & 54.314 & 60.721 & 66.530 & 16,5 \\
\hline 15 & Eslovaquia............. & 50.253 & 39.898 & 49.050 & 57.358 & 60.241 & 61.543 & 61.689 & 66.289 & 31,9 \\
\hline 16 & Rumania ................. & 57.148 & 38.948 & 46.850 & 54.943 & 54.644 & 55.328 & 58.555 & 62.976 & 10,2 \\
\hline 17 & Portugal ................... & 64.194 & 51.379 & 58.647 & 59.551 & 56.374 & 57.013 & 58.976 & 60.162 & $-6,3$ \\
\hline 18 & Finlandia ................. & 62.402 & 43.655 & 51.899 & 60.535 & 59.517 & 58.407 & 57.769 & 54.251 & $-13,1$ \\
\hline 19 & Grecia ..................... & 64.857 & 52.087 & 50.741 & 48.474 & 49.291 & 46.808 & 48.004 & 43.639 & $-32,7$ \\
\hline 20 & Eslovenia................ & 25.180 & 19.053 & 22.720 & 25.525 & 24.934 & 25.129 & 25.551 & 26.789 & 6,4 \\
\hline 21 & Bulgaria .................... & 25.094 & 16.876 & 19.245 & 23.407 & 25.460 & 25.829 & 26.118 & 26.408 & 5,2 \\
\hline 22 & Lituania.................... & 21.144 & 13.123 & 17.653 & 22.826 & 24.879 & 26.208 & 25.889 & 25.397 & 20,1 \\
\hline 23 & Luxemburgo ........... & 21.864 & 18.160 & 18.713 & 20.733 & 21.437 & 20.266 & 20.099 & 20.878 & $-4,5$ \\
\hline 24 & Croacia ..................... & 20.817 & 15.218 & 15.137 & 16.281 & 16.214 & 16.581 & 17.154 & 18.558 & $-10,9$ \\
\hline 25 & Estonia .................... & 10.896 & 7.270 & 9.268 & 12.543 & 14.077 & 13.899 & 13.775 & 13.074 & 20,0 \\
\hline 26 & Letonia..................... & 10.975 & 7.034 & 8.819 & 11.703 & 13.409 & 13.451 & 13.285 & 12.900 & 17,5 \\
\hline 27 & Malta......................... & 3.604 & 3.210 & 3.818 & 4.520 & 5.135 & 4.625 & 5.132 & 5.220 & 44,8 \\
\hline 28 & Chipre ...................... & 7.237 & 5.617 & 6.464 & 6.234 & 5.678 & 4.754 & 5.089 & 5.016 & $-30,7$ \\
\hline \multicolumn{2}{|l|}{ Total . } & 4.250 .068 & 3.383 .556 & 4.013.658 & 4.481 .127 & 4.564 .049 & 4.457.205 & 4.545 .892 & 4.706 .640 & 10,7 \\
\hline
\end{tabular}




\section{LA EVOLUCIÓN DEL COMERCIO EXTERIOR ESPAÑOL DE ALTA TECNOLOGÍA}

\begin{tabular}{|c|c|c|c|c|c|c|c|c|c|c|}
\hline \multirow[b]{2}{*}{ Ranking } & \multicolumn{9}{|c|}{$\begin{array}{l}\text { CUADRO } 19 \\
\text { UE. IMPORTACIONES DE PRODUCTOS DE ALTA TECNOLOGIA DE LOS EEMM, DE MAYOR A MENOR EN } 2015 \\
\text { (En millones de euros) }\end{array}$} & \multirow[b]{2}{*}{$\begin{array}{c}\text { Var. (\%) } \\
\text { 2015/2008 }\end{array}$} \\
\hline & País & 2008 & 2009 & 2010 & 2011 & 2012 & 2013 & 2014 & 2015 & \\
\hline 1 & Alemania ……............. & 107.370 & 99.212 & 124.248 & 126.495 & 126.314 & 125.554 & 134.111 & 147.426 & 37,3 \\
\hline 2 & Reino Unido.............. & 67.104 & 62.138 & 78.007 & 71.860 & 82.316 & 82.702 & 85.280 & 98.357 & 46,6 \\
\hline 3 & Países Bajos ......... & 64.794 & 58.688 & 69.761 & 69.619 & 77.302 & 74.827 & 76.100 & 91.777 & 41,6 \\
\hline 4 & Francia ………...... & 61.633 & 60.382 & 68.703 & 71.423 & 74.527 & 73.127 & 73.561 & 77.677 & 26,0 \\
\hline 5 & Italia …………….. & 31.427 & 29.154 & 40.492 & 39.134 & 34.647 & 32.859 & 33.448 & 37.314 & 18,7 \\
\hline 6 & Bélgica................... & 21.533 & 22.655 & 24.499 & 25.431 & 29.192 & 29.451 & 32.655 & 34.915 & 62,1 \\
\hline 7 & España & 28.491 & 19.914 & 22.559 & 21.773 & 20.396 & 20.218 & 21.675 & 25.126 & $-11,8$ \\
\hline 8 & República Checa.. & 14.600 & 13.069 & 18.190 & 18.964 & 18.608 & 17.802 & 19.760 & 23.100 & 58,2 \\
\hline 9 & Polonia …………....... & 14.041 & 12.617 & 15.611 & 15.367 & 16.277 & 16.913 & 19.047 & 22.073 & 57,2 \\
\hline 10 & Austria ................................. & 13.262 & 11.939 & 13.927 & 14.361 & 16.185 & 18.171 & 17.610 & 19.195 & 44,7 \\
\hline 11 & Irlanda .................... & 13.236 & 11.729 & 9.085 & 8.891 & 9.377 & 13.776 & 16.803 & 18.476 & 39,6 \\
\hline 12 & Suecia .................... & 14.493 & 12.823 & 16.792 & 18.076 & 17.844 & 16.066 & 16.287 & 17.563 & 21,2 \\
\hline 13 & Hungría......................... & 12.697 & 11.061 & 13.484 & 13.856 & 13.025 & 12.736 & 11.795 & 14.036 & 10,5 \\
\hline 14 & Eslovaquia ............... & 4.942 & 4.219 & 5.358 & 7.262 & 9.198 & 10.173 & 10.294 & 11.317 & 129,0 \\
\hline 15 & Dinamarca .............. & 7.506 & 7.148 & 7.190 & 7.548 & 8.521 & 8.064 & 8.335 & 8.690 & 15,8 \\
\hline 16 & Rumania .......................... & 4.956 & 4.196 & 5.701 & 5.924 & 5.222 & 5.589 & 5.879 & 6.787 & 36,9 \\
\hline 17 & Finlandia ....................... & 8.420 & 6.114 & 5.853 & 5.992 & 5.903 & 5.543 & 5.740 & 6.342 & $-24,7$ \\
\hline 18 & Luxemburgo ........... & 5.942 & 5.256 & 3.590 & 3.478 & 4.352 & 3.778 & 3.516 & 4.730 & $-20,4$ \\
\hline 19 & Portugal ..................... & 6.440 & 4.956 & 4.731 & 4.344 & 4.190 & 4.262 & 4.522 & 4.626 & $-28,2$ \\
\hline 20 & 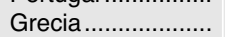 & 5.261 & 4.716 & 4.317 & 3.634 & 3.437 & 2.952 & 3.091 & 3.498 & $-33,5$ \\
\hline 21 & Bulgaria ...................... & 1.572 & 1.219 & 1.434 & 1.820 & 2.264 & 1.795 & 1.964 & 2.148 & 36,6 \\
\hline 22 & 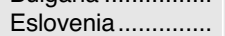 & 1.790 & 1.439 & 1.688 & 1.700 & 1.601 & 1.622 & 1.761 & 1.929 & 7,8 \\
\hline 23 & Lituania .......................... & 1.064 & 720 & 881 & 1.103 & 1.257 & 1.415 & 1.624 & 1.899 & 78,5 \\
\hline 24 & Estonia .................... & 869 & 621 & 1.145 & 1.892 & 1.927 & 1.895 & 2.034 & 1.865 & 114,6 \\
\hline 25 & Croacia ........................ & 1.650 & 1.353 & 1.288 & 1.229 & 1.250 & 1.399 & 1.346 & 1.591 & $-3,6$ \\
\hline 26 & Letonia........................... & 774 & 501 & 669 & 973 & 965 & 1.111 & 1.349 & 1.354 & 74,9 \\
\hline 27 & Malta............................ & 874 & 780 & 849 & 946 & 849 & 868 & 924 & 886 & 1,4 \\
\hline 28 & Chipre ................... & 481 & 407 & 790 & 471 & 353 & 318 & 343 & 366 & $-23,9$ \\
\hline \multicolumn{2}{|c|}{ Total ………… } & 517.222 & 469.026 & 560.842 & 563.566 & 587.299 & 584.986 & 610.854 & 685.063 & 32,5 \\
\hline
\end{tabular}

economías solo comparte la caída con Italia en donde retroceden un 3,5 por 100 (Cuadro 18).

\subsubsection{Importaciones de productos de alta tecnología}

En 2015, en términos absolutos España fue el $7^{\circ}$ importador de productos de alta tecnología de la UE con 21.455 millones de euros, descendiendo una posición con respecto al año 2008. En el periodo 2008-2015 las importaciones de este tipo de productos han descendido un 11,8 por 100 , lo que contrasta con el incremento experimentado en el conjunto de la UE (32,5 por $100)$, y es la única tasa negativa de entre sus cinco principales economías (Cuadro 19).

Asimismo, en 2015 las importaciones españolas de alta tecnología representaron el 3,7 por 100 de las importaciones de estos productos de la UE, 1,8 puntos porcentuales menos que en 2008. De nuevo, Alemania encabeza el ranking, concentrando el 21,5 por 100 de las importaciones de alta tecnología de la UE en su conjunto, seguida a cierta distancia por el Reino Unido con 14,4 por 100.

\subsubsection{Importaciones de productos de alta tecnología sobre importaciones totales}

En 2015, las importaciones españolas de alta tecnología representaron el 8,9 por 100 de las importaciones totales españolas, lejos del 17,4 por 100 que representaron en el Reino Unido, del 15,6 por 100 en Alemania o del 14,6 por 100 en el conjunto de la UE. No obstante, en España el peso ha descendido con respecto el 10,0 por 100 de 2008, mientras que en Alemania han aumentado desde 13,3 por 100 desde ese mismo año. Con respecto a esta ratio, España se situó en el puesto 21 de la UE, lista que encabezó Irlanda con el 27,7 por 100 (Cuadro 20).

\subsubsection{Saldo comercial y tasa de cobertura de productos de alta tecnología}

En el periodo 2008-2015, España ha registrado déficit de productos de alta tecnología en $\triangle$ 


\begin{tabular}{|c|c|c|c|c|c|c|c|c|c|c|}
\hline \multicolumn{11}{|c|}{$\begin{array}{l}\text { CUADRO } 20 \\
\text { UE. IMPORTACIONES DE PROD. DE ALTA TECNOLOGÍA S. EXPORTACIONES TOTALES DE CADA EM, DE MAYOR A MENOR EN } 2015 \\
\text { (En porcentaje) }\end{array}$} \\
\hline Ranking & País & 2008 & 2009 & 2010 & 2011 & 2012 & 2013 & 2014 & 2015 & $\begin{array}{c}\text { Var. (pp) } \\
2015 / 2008\end{array}$ \\
\hline 1 & Irlanda ....................... & 23,2 & 26,1 & 20,0 & 18,6 & 19,2 & 25,4 & 27,7 & 27,7 & 4,5 \\
\hline 2 & Luxemburgo .......... & 27,2 & 28,9 & 19,2 & 16,8 & 20,3 & 18,6 & 17,5 & 22,6 & $-4,6$ \\
\hline 3 & Países Bajos ......... & 16,4 & 18,5 & 18,0 & 16,3 & 16,9 & 16,9 & 17,2 & 20,1 & 3,7 \\
\hline 4 & República Checa.. & 15,1 & 17,4 & 19,0 & 17,4 & 16,9 & 16,4 & 17,0 & 18,2 & 3,1 \\
\hline 5 & Reino Unido............ & 15,0 & 16,7 & 17,5 & 14,7 & 15,2 & 16,6 & 16,4 & 17,4 & 2,4 \\
\hline 6 & Eslovaquia............. & 9,8 & 10,6 & 10,9 & 12,7 & 15,3 & 16,5 & 16,7 & 17,1 & 7,3 \\
\hline 7 & Malta ........................ & 24,3 & 24,3 & 22,2 & 20,9 & 16,5 & 18,8 & 18,0 & 17,0 & $-7,3$ \\
\hline 8 & Hungría................... & 17,1 & 19,8 & 20,3 & 18,8 & 17,6 & 16,9 & 14,9 & 16,8 & $-0,3$ \\
\hline 9 & Alemania ................ & 13,3 & 14,9 & 15,6 & 14,0 & 14,1 & 14,1 & 14,8 & 15,6 & 2,3 \\
\hline 10 & 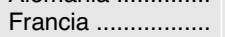 & 12,6 & 14,9 & 14,9 & 13,8 & 14,2 & 14,3 & 14,4 & 15,1 & 2,5 \\
\hline 11 & Estonia .................. & 8,0 & 8,5 & 12,4 & 15,1 & 13,7 & 13,6 & 14,8 & 14,3 & 6,3 \\
\hline 12 & Suecia ...................... & 12,7 & 14,9 & 14,9 & 14,2 & 13,9 & 13,3 & 13,3 & 14,1 & 1,4 \\
\hline 13 & Austria .................... & 10,6 & 11,6 & 11,6 & 10,4 & 11,6 & 13,2 & 12,9 & 13,7 & 3,1 \\
\hline 14 & Polonia ................... & 9,9 & 11,8 & 11,6 & 10,2 & 10,5 & 10,8 & 11,3 & 12,6 & 2,7 \\
\hline 15 & Finlandia ................ & 13,5 & 14,0 & 11,3 & 9,9 & 9,9 & 9,5 & 9,9 & 11,7 & $-1,8$ \\
\hline 16 & Dinamarca .............. & 10,1 & 12,0 & 11,5 & 11,0 & 11,9 & 11,1 & 11,1 & 11,3 & 1,2 \\
\hline 17 & Rumania ................. & 8,7 & 10,8 & 12,2 & 10,8 & 9,6 & 10,1 & 10,0 & 10,8 & 2,1 \\
\hline 18 & Letonia.................... & 7,1 & 7,1 & 7,6 & 8,3 & 7,2 & 8,3 & 10,2 & 10,5 & 3,4 \\
\hline 19 & Bélgica..................... & 6,8 & 8,9 & 8,3 & 7,6 & 8,5 & 8,7 & 9,5 & 10,2 & 3,4 \\
\hline 20 & Italia ........................... & 8,2 & 9,8 & 11,0 & 9,7 & 9,1 & 9,1 & 9,4 & 10,1 & 1,9 \\
\hline 21 & 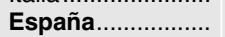 & 10,0 & 9,5 & 9,1 & 8,0 & 7,8 & 7,9 & 8,0 & 8,9 & $-1,1$ \\
\hline 22 & Croacia ..................... & 7,9 & 8,9 & 8,5 & 7,5 & 7,7 & 8,4 & 7,8 & 8,6 & 0,7 \\
\hline 23 & 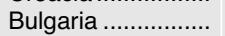 & 6,3 & 7,2 & 7,5 & 7,8 & 8,9 & 6,9 & 7,5 & 8,1 & 1,8 \\
\hline 24 & Grecia ...................... & 8,1 & 9,1 & 8,5 & 7,5 & 7,0 & 6,3 & 6,4 & 8,0 & $-0,1$ \\
\hline 25 & Portugal .................. & 10,0 & 9,6 & 8,1 & 7,3 & 7,4 & 7,5 & 7,7 & 7,7 & $-2,3$ \\
\hline 26 & Lituania .................... & 5,0 & 5,5 & 5,0 & 4,8 & 5,1 & 5,4 & 6,3 & 7,5 & 2,5 \\
\hline 27 & 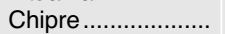 & 6,7 & 7,2 & 12,2 & 7,6 & 6,2 & 6,7 & 6,7 & 7,3 & 0,6 \\
\hline 28 & Eslovenia ............... & 7,1 & 7,6 & 7,4 & 6,7 & 6,4 & 6,5 & 6,9 & 7,2 & 0,1 \\
\hline \multicolumn{2}{|l|}{ Total . } & 12,2 & 13,9 & 14,0 & 12,6 & 12,9 & 13,1 & 13,4 & 14,6 & 2,4 \\
\hline
\end{tabular}

\begin{tabular}{|c|c|c|c|c|c|c|c|c|c|}
\hline \multirow[b]{2}{*}{ Ranking } & \multicolumn{9}{|c|}{$\begin{array}{l}\text { CUADRO } 21 \\
\text { UE. SALDO COMERCIAL DE PRODUCTOS DE ALTA TECNOLOGÍA DE LOS EEMM, DE MAYOR A MENOR EN } 2015 \\
\text { (En millones de euros) }\end{array}$} \\
\hline & País & 2008 & 2009 & 2010 & 2011 & 2012 & 2013 & 2014 & 2015 \\
\hline 1 & Alemania & 14.934 & 13.429 & 8.947 & 16.008 & 28.908 & 29.697 & 26.318 & 29.537 \\
\hline 2 & 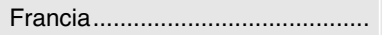 & 11.988 & 8.299 & 11.908 & 8.587 & 14.087 & 16.096 & 17.076 & 20.769 \\
\hline 3 & 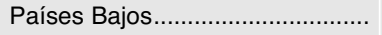 & 5.295 & 6.933 & 10.777 & 12.705 & 18.477 & 14.732 & 18.230 & 10.391 \\
\hline 4 & Irlanda & 7.520 & 6.622 & 7.557 & 9.405 & 9.430 & 4.592 & 2.764 & 8.141 \\
\hline 5 & 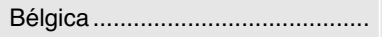 & 268 & 707 & 1.341 & 825 & 532 & 1.289 & 2.070 & 2.051 \\
\hline 6 & Dinamarca & 1.009 & 1.167 & -428 & -106 & -773 & -341 & -97 & 471 \\
\hline 7 & 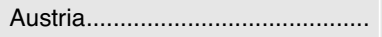 & 96 & -430 & -307 & -89 & 409 & 615 & 1.660 & 312 \\
\hline 8 & Chipre & -269 & -226 & -585 & -277 & -194 & -42 & -219 & -44 \\
\hline 9 & 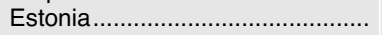 & -231 & -171 & -233 & -112 & -158 & -60 & -66 & -70 \\
\hline 10 & 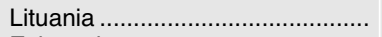 & -16 & -31 & 64 & 33 & 76 & 20 & -28 & -169 \\
\hline 11 & 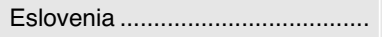 & -585 & -406 & -521 & -378 & -298 & -217 & -312 & -234 \\
\hline 12 & Letonia & -455 & -207 & -325 & -340 & -259 & -235 & -292 & -289 \\
\hline 13 & Malta & 32 & -58 & 42 & 2 & 131 & -84 & -291 & -323 \\
\hline 14 & Suecia & 1.970 & 907 & 530 & 457 & -608 & 397 & -283 & -491 \\
\hline 15 & 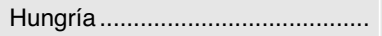 & 2.231 & 2.174 & 2.184 & 3.005 & 934 & 469 & 293 & -525 \\
\hline 16 & 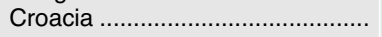 & -1.010 & -783 & -669 & -670 & -559 & -649 & -660 & -767 \\
\hline 17 & República Checa & -485 & -738 & -2.067 & 229 & 1.057 & 629 & 408 & -1.070 \\
\hline 18 & 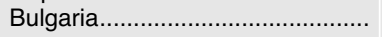 & nd & nd & nd & nd & -1.470 & nd & -1.095 & -1.079 \\
\hline 19 & 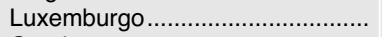 & 278 & 1.157 & 764 & 385 & -378 & -741 & -698 & -1.667 \\
\hline 20 & Grecia & -4.200 & -3.737 & -3.342 & -2.627 & -2.552 & -2.237 & -2.089 & -2.303 \\
\hline 21 & 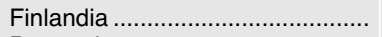 & 2.945 & 136 & -612 & -1.454 & -1.738 & -2.079 & -2.009 & -2.556 \\
\hline 22 & 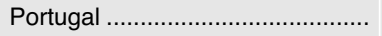 & -3.973 & -3.797 & -3.601 & -3.030 & -2.698 & -2.653 & -2.783 & -2.741 \\
\hline 23 & 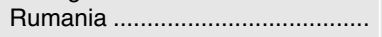 & -3.137 & -1.807 & -2.031 & -1.932 & -2.384 & -2.823 & -2.503 & -2.787 \\
\hline 24 & 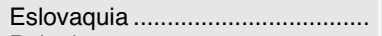 & -2.426 & -1.861 & -2.142 & -3.483 & -4.034 & -3.943 & -3.858 & -4.670 \\
\hline 25 & 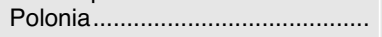 & -9.091 & -7.032 & -8.322 & -8.404 & -7.683 & -6.639 & -5.925 & -6.823 \\
\hline 26 & Italia & -9.491 & -9.305 & -18.401 & -14.910 & -9.847 & -6.930 & -6.689 & -8.872 \\
\hline 27 & España & -20.525 & -12.121 & -13.440 & -11.190 & -8.949 & -7.193 & -9.069 & -11.443 \\
\hline 28 & 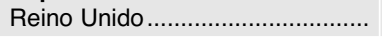 & -17.519 & -13.627 & -22.526 & -12.157 & -18.210 & -19.761 & -25.903 & -29.035 \\
\hline
\end{tabular}




\section{LA EVOLUCIÓN DEL COMERCIO EXTERIOR ESPAÑOL DE ALTA TECNOLOGÍA}

\begin{tabular}{|c|c|c|c|c|c|c|c|c|c|c|}
\hline \multirow[b]{2}{*}{ Ranking } & \multicolumn{10}{|c|}{$\begin{array}{l}\text { CUADRO } 22 \\
\text { UE. TASA DE COBERTURA DE PRODUCTOS DE ALTA TECNOLOGIA DE LOS EEMM, DE MAYOR A MENOR EN } 2015 \\
\text { (En porcentaje) }\end{array}$} \\
\hline & País & 2008 & 2009 & 2010 & 2011 & 2012 & 2013 & 2014 & 2015 & $\begin{array}{c}\text { Var. (pp) } \\
2015 / 2008\end{array}$ \\
\hline 1 & Irlanda ........................ & 156,8 & 156,5 & 183,2 & 205,8 & 200,6 & 133,3 & 116,4 & 144,1 & $-12,8$ \\
\hline 2 & Francia .................... & 119,5 & 113,7 & 117,3 & 112,0 & 118,9 & 122,0 & 123,2 & 126,7 & 7,3 \\
\hline 3 & Alemania ................ & 113,9 & 113,5 & 107,2 & 112,7 & 122,9 & 123,7 & 119,6 & 120,0 & 6,1 \\
\hline 4 & Países Bajos ......... & 108,2 & 111,8 & 115,4 & 118,2 & 123,9 & 119,7 & 124,0 & 111,3 & 3,1 \\
\hline 5 & Bélgica..................... & 101,2 & 103,1 & 105,5 & 103,2 & 101,8 & 104,4 & 106,3 & 105,9 & 4,6 \\
\hline 6 & Dinamarca .............. & 113,4 & 116,3 & 94,0 & 98,6 & 90,9 & 95,8 & 98,8 & 105,4 & $-8,0$ \\
\hline 7 & Austria ..................... & 100,7 & 96,4 & 97,8 & 99,4 & 102,5 & 103,4 & 109,4 & 101,6 & 0,9 \\
\hline 8 & Suecia ..................... & 113,6 & 107,1 & 103,2 & 102,5 & 96,6 & 102,5 & 98,3 & 97,2 & $-16,4$ \\
\hline 9 & Hungría..................... & 117,6 & 119,7 & 116,2 & 121,7 & 107,2 & 103,7 & 102,5 & 96,3 & $-21,3$ \\
\hline 10 & Estonia .................... & 73,4 & 72,5 & 79,7 & 94,1 & 91,8 & 96,8 & 96,8 & 96,2 & 22,8 \\
\hline 11 & República Checa.. & 96,7 & 94,4 & 88,6 & 101,2 & 105,7 & 103,5 & 102,1 & 95,4 & $-1,3$ \\
\hline 12 & Lituania .................. & 98,5 & 95,7 & 107,3 & 103,0 & 106,0 & 101,4 & 98,3 & 91,1 & $-7,4$ \\
\hline 13 & Chipre ..................... & 44,1 & 44,5 & 25,9 & 41,2 & 45,0 & 86,8 & 36,2 & 88,0 & 43,9 \\
\hline 14 & Eslovenia................ & 67,3 & 71,8 & 69,1 & 77,8 & 81,4 & 86,6 & 82,3 & 87,9 & 20,6 \\
\hline 15 & Letonia.................... & 41,2 & 58,7 & 51,4 & 65,1 & 73,2 & 78,8 & 78,4 & 78,7 & 37,4 \\
\hline 16 & Italia ......................... & 69,8 & 68,1 & 54,6 & 61,9 & 71,6 & 78,9 & 80,0 & 76,2 & 6,4 \\
\hline 17 & Reino Unido............ & 73,9 & 78,1 & 71,1 & 83,1 & 77,9 & 76,1 & 69,6 & 70,5 & $-3,4$ \\
\hline 18 & Polonia .................... & 35,3 & 44,3 & 46,7 & 45,3 & 52,8 & 60,7 & 68,9 & 69,1 & 33,8 \\
\hline 19 & Luxemburgo .......... & 104,7 & 122,0 & 121,3 & 111,1 & 91,3 & 80,4 & 80,1 & 64,8 & $-39,9$ \\
\hline 20 & Malta........................ & 103,7 & 92,6 & 104,9 & 100,2 & 115,4 & 90,3 & 68,5 & 63,5 & $-40,1$ \\
\hline 21 & Finlandia ................. & 135,0 & 102,2 & 89,5 & 75,7 & 70,6 & 62,5 & 65,0 & 59,7 & $-75,3$ \\
\hline 22 & Rumania .................. & 36,7 & 56,9 & 64,4 & 67,4 & 54,3 & 49,5 & 57,4 & 58,9 & 22,2 \\
\hline 23 & Eslovaquia .............. & 50,9 & 55,9 & 60,0 & 52,0 & 56,1 & 61,2 & 62,5 & 58,7 & 7,8 \\
\hline 24 & España ................... & 28,0 & 39,1 & 40,4 & 48,6 & 56,1 & 64,4 & 58,2 & 54,5 & 26,5 \\
\hline 25 & Croacia ................... & 38,8 & 42,1 & 48,1 & 45,5 & 55,3 & 53,6 & 51,0 & 51,8 & 13,0 \\
\hline 26 & Bulgaria ................... & nd & nd & nd & nd & 35,1 & nd & 44,2 & 49,8 & nd \\
\hline 27 & Portugal .................... & 38,3 & 23,4 & 23,9 & 30,2 & 35,6 & 37,8 & 38,5 & 40,7 & 2,4 \\
\hline 28 & Grecia ................... & 20,2 & 20,8 & 22,6 & 27,7 & 25,7 & 24,2 & 32,4 & 34,2 & 14,0 \\
\hline
\end{tabular}

todos los años, siendo el de 2015 el segundo mayor de la UE, por detrás del Reino Unido. No obstante, el déficit de 2015 de 11.443 millones es claramente inferior al registrado en el año 2008 (20.525 millones). El extremo contrario lo encabeza Alemania con un superávit de este tipo de productos de 29.537 millones de euros (Cuadro 21).

En 2015 la tasa de cobertura del comercio exterior de bienes en su conjunto alcanzó en España el 90,8 por 100, situándose en un término medio dentro de la UE (posición 15), aunque por debajo de la tasa de cobertura de la UE (103,3 por 100). España destaca por la mejora de 23,9 puntos porcentuales con respecto a la tasa de cobertura del año 2008 (66,9 por 100).

Por su parte, la tasa de cobertura española de alta tecnología alcanzó el 54,5 por 100 en 2015, situándose en la posición 24 dentro del ranking de países de la UE. No obstante, ha mejorado en 26,5 puntos porcentuales con respecto a la tasa de 28,0 por 100 alcanzada en 2008 (Cuadro 22). En 2015, la tasa de cobertura de productos de alta tecnología $(54,5$ por 100$)$ se sitúa 36,5 puntos por debajo de la tasa de cobertura del conjunto de productos $(90,8$ por 100$)$.

\section{Conclusiones}

Cara y cruz en el análisis del comercio exterior español de productos de alta tecnología. La cara es la positiva evolución que ha experimentado el comercio de este tipo de productos, tanto en el incremento de las exportaciones como en la significativa reducción del déficit comercial. Y la cruz está en el relativo bajo peso que supone sobre la producción y el comercio exterior de este tipo de productos en comparación con el de la UE en su conjunto $\triangleright$ 
y con el de las principales economías de nuestro entorno.

Con datos de Eurostat, las exportaciones de este tipo de productos se ha incrementado un 71,8 por 100 en el periodo 2008-2015, superando con creces el aumento experimentado por el conjunto de las exportaciones españolas, del 33,5 por 100, así como el de las exportaciones de productos de alta tecnología de la UE, del 38,3 por 100, además de resultar la mayor tasa de entre sus cinco principales economías.

Este hecho, unido a la caída de las importaciones de productos de alta tecnología en un 11,8 por 100 en el mismo periodo, ha resultado en una reducción del déficit a prácticamente la mitad, desde los 20.525 millones de euros en 2008 a los 11.443 millones de 2015. Consecuentemente, la tasa de cobertura de este tipo de productos ha mejorado significativamente en el periodo analizado hasta el 54,5 por 100 en $2015 ; 26,5$ puntos porcentuales más que en 2008, si bien se sitúa 36,5 puntos por debajo de la tasa de cobertura de 2015 para el conjunto de bienes $(90,8$ por 100$)$.

En un entorno altamente globalizado, destaca el buen comportamiento de determinados grupos de productos que compiten con fuerza en los mercados internacionales. Así, las exportaciones de productos farmacéuticos se han incrementado en un 140,1 por 100 en el periodo 2008-2014 con datos INE, las de maquinaria y material eléctrico un 98,8 por 100 y las de construcción aeronáutica y espacial un 73,6 por 100 .

Asimismo, la evolución de la ratio entre las exportaciones y la producción de productos de alta tecnología con datos del INE muestra un gran avance en el periodo 2008-2014, pasando desde el 82,8 por 100 hasta el 148,2 por 100 de la producción de este tipo de productos, lo que implica una mayor integración de España en las cadenas de valor global, al incluir en los bienes exportados productos producidos en el exterior.
A pesar de estos avances, los productos de alta tecnología siguen teniendo todavía un peso reducido en el comercio exterior español si lo comparamos con el del resto de países de la UE. Así, en España la ratio de las exportaciones de productos de alta tecnología sobre las exportaciones totales calculada con datos de Eurostat alcanzó el 5,4 por 100, lejos del 24,2 por 100 que representaron en Alemania o del 14,0 por 100 en el conjunto de la UE, si bien se ha incrementado en 1,2 puntos porcentuales con respecto a la del año 2008. Las importaciones españolas de alta tecnología representaron, por su parte, el 8,9 por 100 de las importaciones totales españolas, también lejos del 14,6 por 100 del conjunto de la UE, y su peso ha descendido con respecto al 10,0 por 100 registrado por España en 2008.

Esta relativa baja participación de los productos de alta tecnología en el comercio exterior español puede estar influenciado por el bajo peso, en España, de las empresas manufactureras de tecnología alta sobre el total de empresas manufactureras $(1,6$ por 100$)$ y de tecnología media-alta (7,5 por 100), en comparación con los pesos en la UE en su conjunto (2,2 por 100 y 9,7 por 100 respectivamente) o de los países de referencia como Alemania (4,3 por 100 y 14,6 por 100$)$ o Reino Unido (5,1 por 100 y 14,2 por 100$)$.

A fin de poder converger hacia los países europeos de referencia resulta necesario seguir apostando por un entorno favorecedor de la investigación, desarrollo e innovación, a fin de que las empresas puedan competir con mayores garantías en los mercados internacionales y puedan contribuir a un crecimiento robusto y sostenible de nuestra economía.

\section{Bibliografía}

[1] EUROSTAT (2015). Enterprises in high-tech sectors by NACE Rev.2 activity (actualizado en octubre). Disponible en:

http://ec.europa. eu/eurostat 
[2] EUROSTAT (2016) International trade of EU, the euro area and the Member States (actualizado en abril). Disponible en: http://ec. europa.eu/eurostat

[3] EUROSTAT (2016). Trade in HTEC sectors (actualizado en mayo). Disponible en: http://ec. europa.eu/eurostat
[4] INSTITUTO NACIONAL DE ESTADÍSTICA (2015). Indicadores de alta tecnología (actualizado en febrero). Disponible en: www.ine.es

[5] INSTITUTO NACIONAL DE ESTADÍSTICA (2016). Encuesta industrial de empresas (actualizado en diciembre). Disponible en: www.ine.es 


\section{Subdirección General de Evaluación de Instrumentos de Política Comercial}

\section{ANEXOS}

\section{ANEXO 1}

\section{SECTORES DE ALTA Y MEDIA-ALTA TECNOLOGÍA}

\begin{tabular}{|c|c|}
\hline Sectores & CNAE 2009 \\
\hline 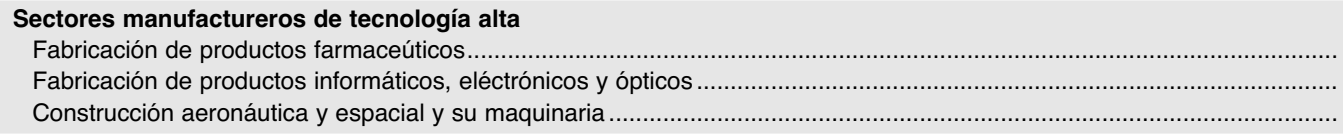 & $\begin{array}{c}21 \\
26 \\
30.3\end{array}$ \\
\hline 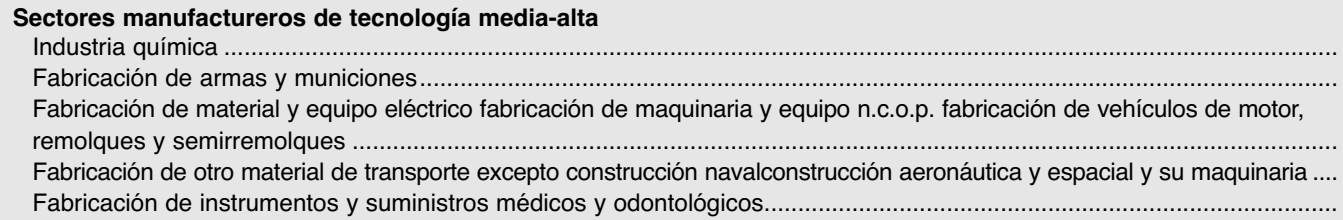 & $\begin{array}{l}20 \\
25.4 \\
27 \text { a } 29 \\
30-30.1-30.3 \\
32.5\end{array}$ \\
\hline
\end{tabular}

\begin{tabular}{|c|c|c|}
\hline \multicolumn{3}{|c|}{$\begin{array}{c}\text { ANEXO } 2 \\
\text { LISTA DE PRODUCTOS DE ALTA TECNOLOGÍA }\end{array}$} \\
\hline Grupo & Sector & Código CUCl rev4 \\
\hline 1 & Construcción aeronáutica y espacial & {$[(714-714.89-714.99)+792.1+792.2+792.3+792.4+792.5+792.91+792.93+874.11]$} \\
\hline 2 & Maquinaria de oficina y eq. informático & {$[751.94+751.95+752+759.97]$} \\
\hline 3 & $\begin{array}{l}\text { Mat. electrónico, eq. y ap. radio, TV } \\
\text { y comunic. }\end{array}$ & $\begin{array}{c}{[763.31+763.8+(764-764.93-764.99)+772.2+772.61+773.18+776.25+776.27+} \\
776.3+776.4+776.8+898.44+898.46]\end{array}$ \\
\hline 4 & Productos farmacéuticos & {$[541.3+541.5+541.6+542.1+542.2]$} \\
\hline 5 & Instrumentos científicos & $\begin{array}{c}{[774+871+872.11+(874-874.11-874.2)+881.11+881.21+884.11+884.19+(899.6-} \\
899.65-899.69)]\end{array}$ \\
\hline 6 & Maquinaria y material eléctrico & {$[(778.6-778.61-778.66-778.69)+778.7+778.84]$} \\
\hline 7 & Productos químicos & {$[52222+52223+52229+52269+525+531+57433+591]$} \\
\hline 8 & Maquinaria y equipo mecánico & $\begin{array}{c}{[714.89+714.99+718.7+728.47+731.1+731.31+731.35+731.42+731.44+731.51+} \\
731.53+731.61+731.63+731.65+733.12+733.14+733.16+735.9+737.33+737.35]\end{array}$ \\
\hline 9 & Armas y municiones & {$[891]$} \\
\hline
\end{tabular}




\begin{tabular}{|c|c|c|c|c|c|c|c|}
\hline \multicolumn{8}{|c|}{$\begin{array}{l}\text { ANEXO } 3 \\
\text { VALOR DE LA EXPORTACIÓN DE PRODUCTOS DE ALTA TECNOLOGÍA POR TIPO DE PRODUCTOS } \\
\text { (Miles de euros) }\end{array}$} \\
\hline & 2008 & 2009 & 2010 & 2011 & 2012 & 2013 & 2014 \\
\hline 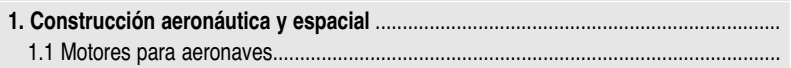 & $\begin{array}{r}1.359 .219 \\
465.014\end{array}$ & $\begin{array}{r}1.397 .221 \\
365.625\end{array}$ & $\begin{array}{r}1.464 .947 \\
491.385\end{array}$ & $\begin{array}{r}1.786 .439 \\
613.426\end{array}$ & $\begin{array}{r}1.960 .541 \\
682.299\end{array}$ & $\begin{array}{r}3.770 .575 \\
660.593\end{array}$ & $\begin{array}{r}2.360 .182 \\
622.695\end{array}$ \\
\hline 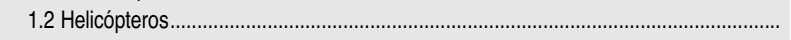 & 7.248 & 3.329 & 54.272 & 26.766 & 19.987 & 65.673 & 15.169 \\
\hline 1.3 Aviones & 841.798 & 992.328 & 892.615 & 1.065 .041 & 1.134 .590 & 2.989 .992 & 1.633 .999 \\
\hline 1.4 Naves espaciales & 0 & 1.353 & 0 & nd & 131 & 0 & 13.011 \\
\hline 1.5 Hélices, rotores y sus partes & 18.928 & 5.294 & 5.218 & 34.881 & 96.665 & 14.243 & 18.628 \\
\hline 1.6 Trenes de aterrizaje y sus partes & 22.626 & 24.340 & 8.494 & 7.392 & 10.670 & 17.607 & 28.294 \\
\hline 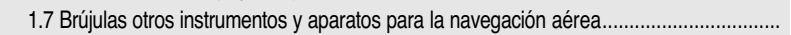 & 3.605 & 4.952 & 12.963 & 38.933 & 16.200 & 22.468 & 28.385 \\
\hline 2. Maquinaria de oficina y equipo informático & 596.386 & 641.716 & 665.267 & 681.862 & 654.062 & 693.250 & 705.746 \\
\hline 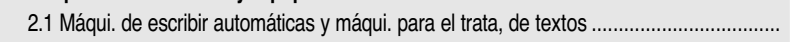 & 32.349 & 18.059 & 23.771 & nd & 31.720 & 28.096 & 23.252 \\
\hline 2.2 Fotocopiadoras & 37.758 & 51.959 & 56.865 & 68.119 & 80.586 & 85.505 & 83.510 \\
\hline 2.3 Ordenadores & 314.813 & 383.514 & 448.877 & 466.447 & 399.934 & 439.512 & 479.143 \\
\hline 2.4 Partes y accesorios de ordenadores & 211.467 & 188.184 & 135.754 & 147.296 & 141.821 & 140.137 & 119.842 \\
\hline 3. Material electrónico equipos y aparatos de radio, televisión y comunicaciones. & 1.677 .516 & 1.784 .491 & 2.575 .321 & 2.285 .864 & 1.892 .749 & 1.711 .825 & 1.928 .070 \\
\hline 3.1 Aparatos de grabación y reproducción de sonido & 497 & 224 & 203 & 140 & 1.567 & 649 & 651 \\
\hline 3.2 Aparatos de vídeo & 35.504 & 30.140 & 25.077 & 70.465 & 66.772 & 55.403 & 51.068 \\
\hline 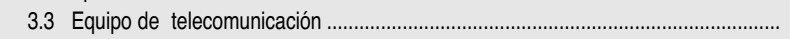 & 671.199 & 643.768 & 687.265 & 729.654 & 871.809 & 837.633 & 1.041 .005 \\
\hline 3.4 Circuitos impresos & 52.354 & 40.291 & 41.971 & 48.627 & 58.430 & 71.971 & 79.918 \\
\hline 3.5 Cuadros y otros soportes con aparatos eléctricos para una tensión $<1.000 \mathrm{~V}$........ & 117.072 & 119.653 & 162.447 & 156.094 & 155.016 & 205.470 & 223.686 \\
\hline 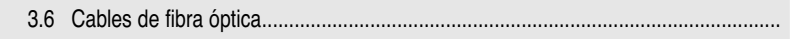 & 63.938 & 64.493 & 80.024 & 82.364 & 104.371 & 101.439 & 83.087 \\
\hline 3.7 y 3.8 Tubos de microondas otras válvulas y tubos & 733 & 771 & 1.616 & 1.282 & 3.651 & 910 & 521 \\
\hline 3.9 Semiconductores & 274.194 & 572.887 & 1.292 .885 & 905.623 & 338.598 & 127.237 & 63.260 \\
\hline 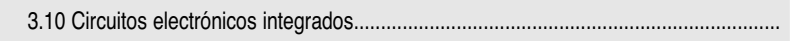 & 212.393 & 92.179 & 112.177 & 103.000 & 120.761 & 155.587 & 218.100 \\
\hline 3.11 Cristales piezoeléctricos & 99.840 & 98.583 & 36.273 & 47.243 & 36.615 & 12.984 & 16.533 \\
\hline 3.12 Soportes ópticos & 93.468 & 82.905 & 83.418 & 74.896 & 52.903 & 61.495 & 50.731 \\
\hline 3.13 Partes semiconductoras & 56.324 & 38.597 & 51.966 & 66.479 & 82.258 & 81.047 & 99.510 \\
\hline 4. Productos farmacéuticos & 1.367 .391 & 1.484 .516 & 1.682 .803 & 2.107 .234 & 3.121.101 & 2.722 .564 & 3.283 .624 \\
\hline 4.1 Antibióticos. & 349.714 & 323.503 & 333.528 & 349.922 & 368.124 & 335.314 & 324.954 \\
\hline 4.2 Hormonas y sus derivados & 45.306 & 49.159 & 63.877 & 61.479 & 90.337 & 106.546 & 110.254 \\
\hline 4.3 Glucósidos, glándulas, sueros, vacunas & 632.117 & 736.055 & 830.602 & 1.145 .512 & 2.094 .747 & 1.652 .752 & 1.935 .766 \\
\hline 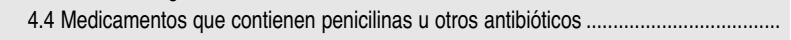 & 140.439 & 168.470 & 189.870 & 239.922 & 254.416 & 283.208 & 318.601 \\
\hline 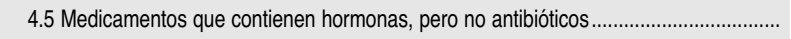 & 199.815 & 207.329 & 264.925 & 310.399 & 313.478 & 344.744 & 594.049 \\
\hline 5. Instrumentos científicos & 649.691 & 634.391 & 761.314 & 855.461 & 999.419 & 933.794 & 1.186 .587 \\
\hline 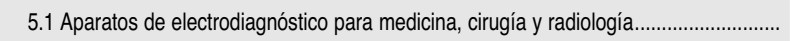 & 148.160 & 141.388 & 167.049 & 175.637 & 195.938 & 184.366 & 207.667 \\
\hline 5.2 Instrumentos y aparatos ópticos & 19.589 & 17.582 & 21.359 & 22.720 & 24.441 & 22.064 & 34.050 \\
\hline 5.3 Tornos dentales & 148 & 1.727 & 1.412 & 1.163 & 1.549 & 1.142 & 1.064 \\
\hline 5.4 Instrumentos y aparatos de medida & 476.108 & 375.388 & 453.665 & 515.177 & 620.046 & 588.892 & 795.316 \\
\hline 5.5 Aparatos fotográficos & 5.686 & 4.661 & 6.485 & 8.833 & 6.479 & 10.021 & 8.915 \\
\hline 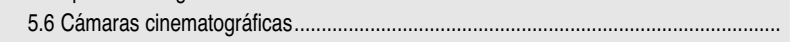 & 254 & 493 & 963 & 264 & 773 & 530 & 1.343 \\
\hline 5.7 Lentes de contacto & 9.026 & 9.620 & 14.500 & 12.928 & 14.877 & 16.933 & 16.522 \\
\hline 5.8 Otras fibras ópticas & 5.630 & 5.868 & 4.146 & 4.826 & 6.389 & 6.294 & 6.939 \\
\hline 5.9 Aparatos de ortopedia & 72.451 & 77.665 & 91.735 & 113.914 & 128.927 & 103.551 & 114.772 \\
\hline 6. Maquinaria y material eléctrico & 166.106 & 139.599 & 174.777 & 266.225 & 244.086 & 310.683 & 330.190 \\
\hline 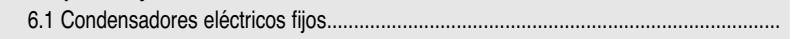 & 7.827 & 5.674 & 6.928 & 9.107 & 8.443 & 10.462 & 11.569 \\
\hline 6.2 Máquinas y aparatos eléctricos con función propia & 121.163 & 89.874 & 123.037 & 202.043 & 183.033 & 232.989 & 247.175 \\
\hline 6.3 Aparatos eléctricos de señalización sonora o visual. & 37.116 & 44.051 & 44.812 & 55.075 & 52.609 & 67.232 & 71.445 \\
\hline 7. Productos químicos & 1.022 .326 & 758.349 & 992.746 & 1.292 .195 & 1.494 .505 & 1.424 .433 & 1.505 .246 \\
\hline 7.1 Selenio, teluro, fósforo, arsenio y boro & 379 & 82 & 291 & 378 & 165 & 88 & 256 \\
\hline 7.2 Silicio & 33.119 & 10.874 & 37.789 & 56.984 & 43.046 & 42.815 & 32.790 \\
\hline 7.3 Calcio, estroncio y bario & 897 & 560 & 1.155 & 1.472 & 554 & 584 & 653 \\
\hline 7.4 Otros productos químicos inorgánicos & 16.637 & 10.985 & 18.414 & 23.969 & 20.065 & 18.698 & 17.838 \\
\hline 7.5 Materias radioactivas. & 73.647 & 4.500 & 7.234 & 8.071 & 8.950 & 3.853 & 1.545 \\
\hline 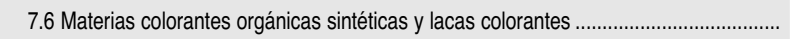 & 177.440 & 154.787 & 196.210 & 193.913 & 212.471 & 215.746 & 226.945 \\
\hline 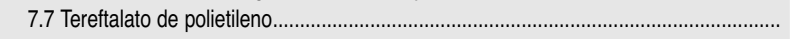 & 153.425 & 94.122 & 164.932 & 270.583 & 289.366 & 229.388 & 251.694 \\
\hline 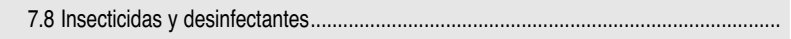 & 566.781 & 482.438 & 566.721 & 736.826 & 919.888 & 913.262 & 973.525 \\
\hline
\end{tabular}

nd: no disponible.

Fuente: INE, Indicadores de Alta Tecnología (a partir de datos del Departamento de Aduanas e IIEE de la AEAT). 


\section{Subdirección General de Evaluación de Instrumentos de Política Comercial}

\begin{tabular}{|c|c|c|c|c|c|c|c|}
\hline \multicolumn{8}{|c|}{$\begin{array}{l}\text { ANEXO } 3 \text { (continuación) } \\
\text { VALOR DE LA EXPORTACIÓN DE PRODUCTOS DE ALTA TECNOLOGÍA POR TIPO DE PRODUCTOS } \\
\text { (Miles de euros) }\end{array}$} \\
\hline & 2008 & 2009 & 2010 & 2011 & 2012 & 2013 & 2014 \\
\hline 8. Maquinaria y equipo mecánico & 850.805 & 777.045 & 652.247 & 1.071.305 & 921.492 & 1.125 .457 & 916.295 \\
\hline 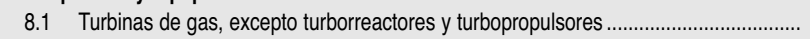 & 5.112 & 12.073 & 7.218 & 12.887 & 2.196 & 6.370 & 8.090 \\
\hline 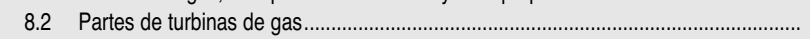 & 53.926 & 40.466 & 37.345 & 42.368 & 45.669 & 47.491 & 30.150 \\
\hline Reactores nucleares & 217.231 & 293.145 & 223.089 & 483.332 & 325.125 & 443.523 & 341.157 \\
\hline Máquinas y equipos para la separación de isótopos........................................... & 156 & 28 & 15 & 7 & 6 & 142 & 1.009 \\
\hline 8.5 Máquinas y herramientas operadas por láser u otro tipo de luz o haz de luz, etc...... & 26.469 & 17.041 & 22.060 & 35.736 & 38.440 & 40.799 & 37.774 \\
\hline Tornos horizontales de control numérico & 52.390 & 43.482 & 54.224 & 69.880 & 73.537 & 85.238 & 86.427 \\
\hline Los demás tornos de control numérico & 2.366 & 2.743 & 14.828 & 7.028 & 15.747 & 18.302 & 13.896 \\
\hline 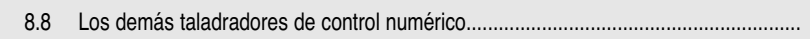 & 5.115 & 3.533 & 3.099 & 23.546 & 8.622 & 10.741 & 4.371 \\
\hline 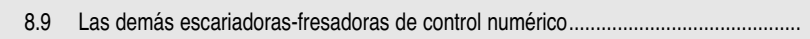 & 14.025 & 12.542 & 7.402 & 8.016 & 15.822 & 11.071 & 8.559 \\
\hline 8.10 Fresadoras Knee-type de control numérico & 5.288 & 1.025 & 1.843 & 2.368 & 1.765 & 2.285 & 1.781 \\
\hline 8.11 La demás fresadoras de control numérico & 221.395 & 132.810 & 62.812 & 124.148 & 122.837 & 134.475 & 106.915 \\
\hline 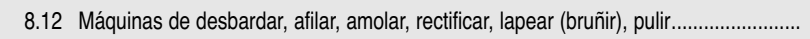 & 21.516 & 17.295 & 4.327 & 11.010 & 22.630 & 13.222 & 16.208 \\
\hline 8.13 La demás máquinas de desbardar, afilar, amolar, rectificar, lapear (bruñir), pulir....... & 16.192 & 14.502 & 15.751 & 24.738 & 29.067 & 38.074 & 36.226 \\
\hline 8.14 Afiladoras de control numérico & 952 & 15 & 1.410 & 1.733 & 534 & 957 & 1.006 \\
\hline 8.15 Máquinas de enrollar, curvar, plegar, enderezar o aplanar, de control numérico ......... & 24.740 & 6.032 & 14.248 & 14.840 & 12.052 & 21.703 & 20.566 \\
\hline 8.16 Fundidoras de control numérico & 16.699 & 5.178 & 12.962 & 17.985 & 4.877 & 8.586 & 7.215 \\
\hline 8.17 Perforadoras de control numérico & 7.228 & 10.607 & 8.697 & 11.254 & 7.542 & 17.751 & 10.622 \\
\hline 8.18 Partes y accesorios destinados a las máquinas de los subgrupos 8.5 a $8.17 \ldots \ldots \ldots \ldots$ & 151.259 & 157.126 & 150.518 & 170.369 & 182.393 & 216.536 & 170.483 \\
\hline 8.19 Máquinas y eq. para soldadura por resistencia de metales, parcial o comp. automat...... & 4.677 & 3.366 & 3.257 & 5.755 & 9.624 & 4.724 & 9.701 \\
\hline 8.20 Máquinas y eq. para soldadura por arco de metales, parcial o comp.automatiz......... & 4.069 & 4.035 & 7.141 & 4.303 & 3.010 & 3.467 & 4.140 \\
\hline 9. Armas y municiones & 152.446 & 173.028 & 174.765 & 93.819 & 119.427 & 181.047 & 175.347 \\
\hline Total & 7.841 .886 & 7.790 .355 & 9.144 .187 & 10.440 .404 & 11.407 .382 & 12.873 .630 & 12.391.287 \\
\hline
\end{tabular}




\begin{tabular}{|c|c|c|c|c|c|c|c|}
\hline \multicolumn{8}{|c|}{$\begin{array}{l}\text { ANEXO } 4 \\
\text { VALOR DE LA IMPORTACIÓN DE PRODUCTOS DE ALTA TECNOLOGÍA POR TIPO DE PRODUCTOS } \\
\text { (Miles de euros) }\end{array}$} \\
\hline & 2008 & 2009 & 2010 & 2011 & 2012 & 2013 & 2014 \\
\hline 1. Construcción aeronáutica y espacial & 2.114 .737 & 1.082 .587 & 1.654 .612 & 1.448 .450 & 1.724 .514 & 1.874 .067 & 1.418.792 \\
\hline 1.1 Motores para aeronaves & 528.370 & 412.633 & 543.119 & 635.128 & 747.086 & 750.706 & 793.112 \\
\hline 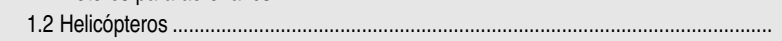 & 138.898 & 123.786 & 109.086 & 72.054 & 41.773 & 17.157 & 71.448 \\
\hline 1.3 Aviones & 1.353 .890 & 446.593 & 802.677 & 608.140 & 818.750 & 964.061 & 412.313 \\
\hline 1.4 Naves espaciales & 0 & 5 & 0 & nd & 0 & 13.590 & \\
\hline 1.5 Hélices, rotores y sus partes. & 11.744 & 11.132 & 13.527 & 19.224 & 20.639 & 23.831 & 14.696 \\
\hline 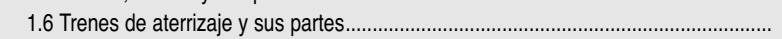 & 34.065 & 34.600 & 58.773 & 40.241 & 34.851 & 41.445 & 51.542 \\
\hline 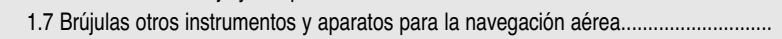 & 47.770 & 53.837 & 127.431 & 73.663 & 61.415 & 63.277 & 75.680 \\
\hline 2. Maquinaria de oficina y equipo & 4.698 .470 & 3.739 .560 & 4.164.588 & 3.423.220 & 3.478 .760 & 3.476 .359 & 3.594 .595 \\
\hline 2.1 Máquinas de escribir automáticas y máquinas para el tratamiento de textos............ & 221.713 & 190.585 & 189.285 & nd & 149.349 & 180.687 & 204.551 \\
\hline 2.2 Fotocopiadoras & 262.686 & 186.874 & 193.632 & 171.995 & 142.667 & 145.337 & 155.293 \\
\hline 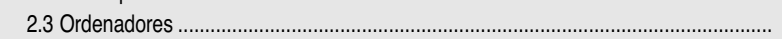 & 3.405 .104 & 2.804 .000 & 3.296 .743 & 2.793 .881 & 2.748 .783 & 2.771 .375 & 2.789 .754 \\
\hline 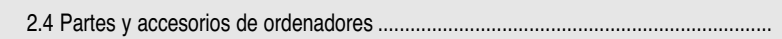 & 808.967 & 558.101 & 484.928 & 457.344 & 437.961 & 378.960 & 444.996 \\
\hline 3. Material electrónico equipos y aparatos de radio, televisión y comunicaciones... & 13.002 .002 & 6.564 .875 & 8.349 .301 & 7.920 .217 & 6.749 .032 & 6.562 .272 & 7.279 .030 \\
\hline 3.1 Aparatos de grabación y reproducción de sonido & 8.633 & 7.335 & 8.870 & 5.026 & 9.581 & 4.223 & 4.034 \\
\hline 3.2 Aparatos de vídeo & 236.139 & 178.398 & 183.670 & 170.109 & 210.347 & 124.614 & 132.126 \\
\hline 3.3 Equipo de telecomunicación......... & 5.079 .889 & 4.201 .238 & 4.895 .691 & 5.342 .829 & 4.688 .116 & 4.770 .635 & 5.233 .298 \\
\hline 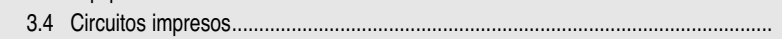 & 183.411 & 134.729 & 171.311 & 161.066 & 141.966 & 155.122 & 164.916 \\
\hline 3.5 Cuadros y otros soportes con aparatos eléctricos para una tensión $<1.000 \mathrm{~V}$....... & 408.996 & 179.751 & 242.004 & 252.636 & 294.950 & 314.585 & \\
\hline 3.6 Cables de fibra óptica & 40.695 & 27.776 & 36.501 & 46.878 & 44.221 & 58.583 & 105.945 \\
\hline 3.7 Tubos de microondas otras válvulas y tubos & 4.537 & 4.753 & 4.619 & 5.117 & 3.761 & 5.622 & 4.389 \\
\hline 3.8 Semiconductores. & 5.856 .816 & 988.970 & 1.857 .607 & 1.032 .961 & 449.905 & 227.814 & 205.346 \\
\hline 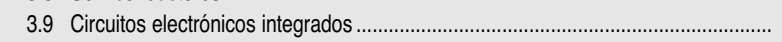 & 597.596 & 420.024 & 457.561 & 455.360 & 453.067 & 442.256 & 474.983 \\
\hline 3.10 Cristales piezoeléctricos ................. & & & & & & & \\
\hline 3.11 Soportes ópticos & 311.931 & 239.319 & 270.380 & 274.947 & 220.629 & 214.438 & 239.890 \\
\hline 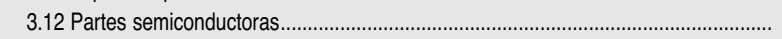 & 125.858 & 140.198 & 159.320 & 139.031 & 204.185 & 225.914 & 292.469 \\
\hline 4. Productos farmacéuticos & 3.163 .253 & 3.804 .669 & 3.346 .534 & 3.537 .386 & 3.281.111 & 2.942 .858 & 3.426 .934 \\
\hline 4.1 Antibióticos & 187.189 & 197.805 & 198.264 & 249.552 & 239.604 & 197.949 & 241.421 \\
\hline 4.2 Hormonas y sus derivados & & & & & & & 99.096 \\
\hline 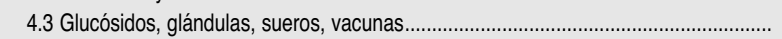 & 1.524 .847 & 1.705 .487 & 1.770 .922 & 1.896 .690 & 1.990 .892 & 1.721 .722 & 1.964 .188 \\
\hline 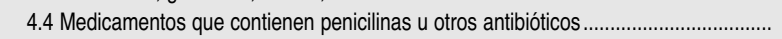 & & & & 296.237 & 251.697 & & \\
\hline 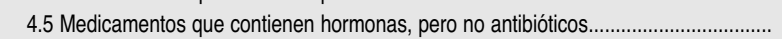 & 919.765 & 990.562 & 1.065 .027 & 1.031 .913 & 717.260 & 657.691 & 820.918 \\
\hline 5. Instrumentos científicos & 1.959 .981 & 2.263 .898 & 2.464 .621 & 2.531 .534 & 2.365 .538 & 2.433 .120 & 2.848 .462 \\
\hline 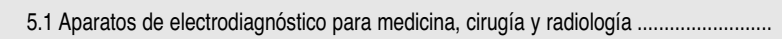 & 513.108 & 412.529 & 435.511 & 354.707 & 297.863 & 342.656 & 382.019 \\
\hline 5.2 Instrumentos y aparatos ópticos & 91.858 & 89.946 & 104.928 & 105.042 & 101.570 & 94.020 & 100.092 \\
\hline 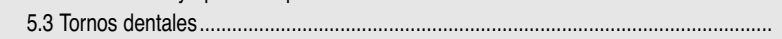 & 2.073 & & 1.977 & & 1.425 & 1.388 & 2.373 \\
\hline 5.4 Instrumentos y aparatos de medida & 1.337 .404 & 1.203 .383 & 1.273 .441 & 1.332 .347 & 1.236 .855 & 1.324 .071 & 1.614 .801 \\
\hline 5.5 Aparatos fotográficos & 15.537 & 6.325 & 5.465 & 6.029 & 4.505 & 4.394 & 5.517 \\
\hline 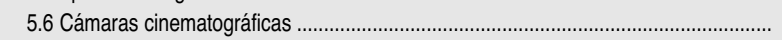 & 771 & 1.000 & 1.023 & 1.133 & 720 & 298 & 421 \\
\hline 5.7 Lentes de contacto & 60.086 & 62.415 & 81.383 & 77.919 & 71.020 & 71.869 & 79.787 \\
\hline & & & & & 38.229 & & 38.575 \\
\hline 5.9 Aparatos de ortopedia & 442.794 & 466.534 & 539.162 & 622.003 & 613.350 & 558.729 & 624.878 \\
\hline 6. Maquinaria y material eléctrico & 724.942 & 536.754 & 592.780 & 562.574 & 604.063 & 759.618 & 873.623 \\
\hline 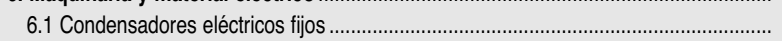 & 65.849 & 35.365 & 49.890 & 46.460 & 61.087 & 77.613 & 103.815 \\
\hline 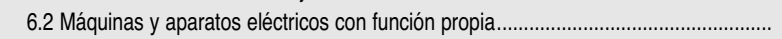 & 375.200 & 278.746 & 303.826 & 317.028 & 363.408 & 469.343 & 551.648 \\
\hline 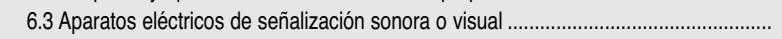 & 283.893 & 222.642 & 239.064 & 199.087 & 179.569 & 212.662 & 218.160 \\
\hline 7. Productos químicos & 1.358 .175 & 1.309 .668 & 1.476.272 & 1.530 .812 & 1.520 .742 & 1.472 .485 & 1.497 .422 \\
\hline 7.1 Selenio, teluro, fósforo, arsenio y boro & 3.414 & 1.417 & 2.449 & 4.161 & 2.916 & 1.989 & 1.711 \\
\hline 7.2 Silicio & 19.793 & 20.658 & 25.419 & 32.713 & 23.537 & 16.260 & 15.886 \\
\hline 7.3 Calcio, estroncio y bario & 4.117 & 1.478 & 3.540 & 1.912 & 2.773 & 3.349 & 3.955 \\
\hline 7.4 Otros productos químicos inorgánicos & 39.378 & 21.463 & 43.462 & 44.267 & 43.780 & 48.854 & 42.190 \\
\hline 7.5 Materias radioactivas & 470.873 & 423.040 & 507.511 & 467.633 & 507.625 & 383.974 & 369.258 \\
\hline 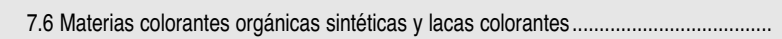 & 199.276 & 190.987 & 199.067 & 201.089 & 195.009 & 210.506 & 223.245 \\
\hline 7.7 Tereftalato de polietileno & 118.098 & 132.831 & 177.476 & 129.899 & 97.227 & 123.403 & 100.219 \\
\hline 7.8 Insecticidas y desinfectantes & 503.226 & 517.794 & 517.346 & 649.137 & 647.876 & 684.150 & 740.958 \\
\hline
\end{tabular}




\section{Subdirección General de Evaluación de Instrumentos de Política Comercial}

\begin{tabular}{|c|c|c|c|c|c|c|c|}
\hline \multicolumn{8}{|c|}{$\begin{array}{l}\text { ANEXO } 4 \text { (continuación) } \\
\text { VALOR DE LA IMPORTACIÓN DE PRODUCTOS DE ALTA TECNOLOGÍA POR TIPO DE PRODUCTOS } \\
\text { (Miles de euros) }\end{array}$} \\
\hline & 2008 & 2009 & 2010 & 2011 & 2012 & 2013 & 2014 \\
\hline 8. Maquinaria y equipo mecánico & 667.504 & 447.089 & 455.322 & 468.047 & 573.105 & 406.055 & 442.579 \\
\hline 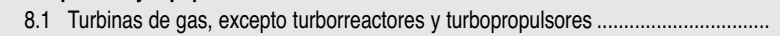 & 31.693 & 55.973 & 11.225 & 53.965 & 127.352 & 13.695 & 3.833 \\
\hline 8.2 Partes de turbinas de gas & 200.857 & 188.121 & 195.317 & 126.518 & 175.093 & 93.782 & 101.086 \\
\hline 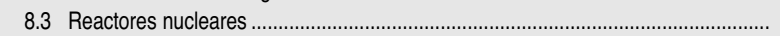 & 52.991 & 26.824 & 42.601 & 17.760 & 9.400 & 42.067 & 31.581 \\
\hline 8.4 Máquinas y equipos para la separación de isótopos................................................... & 611 & 445 & 1.472 & 100 & 2 & 67 & 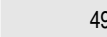 \\
\hline 8.5 Máquinas y herramientas operadas por láser u otro tipo de luz o haz de luz, etc.. & 37.464 & 12.298 & 14.903 & 23.599 & 20.750 & 21.980 & 31.417 \\
\hline 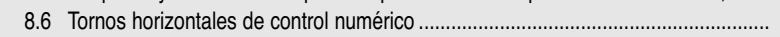 & 41.880 & 8.569 & 17.987 & 31.736 & 32.654 & 40.796 & 52.378 \\
\hline 8.7 Los demás tornos de control numérico. & 7.488 & 5.550 & 1.705 & 6.334 & 1.797 & 4.841 & 5.003 \\
\hline 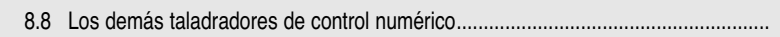 & 538 & 1.053 & 13 & 370 & 6.624 & 4.701 & 885 \\
\hline 8.9 Las demás escariadoras-fresadoras de control numérico ........................................ & 6.835 & 2.926 & 447 & 23 & 1.334 & 489 & 10.580 \\
\hline 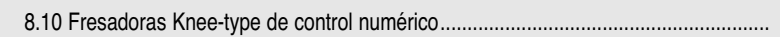 & 571 & 2 & 539 & 89 & 171 & 2 & 806 \\
\hline 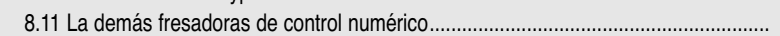 & 5.138 & 4.690 & 2.550 & 3.211 & 2.069 & 2.011 & 6.409 \\
\hline $\begin{array}{l}\text { 8.12 Máqui. de desbardar, afilar, amolar, rectificar, lapear (bruñir), pulir o hacer otras } \\
\text { operaciones de acabado, de control numérico }\end{array}$ & 521 & 1.258 & 441 & 277 & 4.726 & 4.091 & 4.080 \\
\hline 8.13 La demás máquinas de desbardar, afilar, amolar, rectificar, lapear (bruñir), pulir o & & & & & & & \\
\hline hacer otras operaciones de acabado, de control numérico........................................ & 9.193 & 2.581 & 2.332 & 3.716 & 2.378 & 3.739 & 6.085 \\
\hline 8.14 Afiladoras de control numérico & 1.524 & 1.306 & 639 & 2.009 & 1.936 & 662 & 1.819 \\
\hline 8.15 Máquinas de enrollar, curvar, plegar, enderezar o aplanar, de control numérico.... & 30.477 & 12.087 & 20.995 & 18.971 & 13.726 & 11.073 & 12.520 \\
\hline 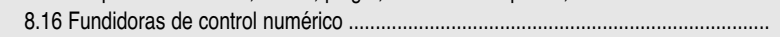 & 5.605 & 3.209 & 11.612 & 5.320 & 3.453 & 3.268 & 6.339 \\
\hline 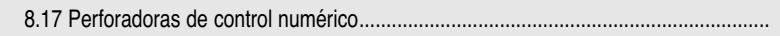 & 31.322 & 18.306 & 15.441 & 12.866 & 25.466 & 21.508 & 37.936 \\
\hline 8.18 Partes y accesorios destinados a las máquinas de los subgrupos 8.5 a $8.17 \ldots \ldots \ldots$. & 151.618 & 75.989 & 93.707 & 130.798 & 107.768 & 107.747 & 112.031 \\
\hline 8.19 Máquinas y equipos para la soldadura por resistencia de metales, parcial o & & & & & & & 6.979 \\
\hline completamente automatizados & 31.389 & 16.725 & 12.554 & 19.794 & 26.748 & 23.126 & \\
\hline 8.20 Máquinas y equipos para la soldadura por arco de metales, parcial o & & & & & & & \\
\hline 9. Armas y municiones automatizados & $\begin{array}{r}19.90 \\
162.921\end{array}$ & $\begin{array}{r}9.1 / 6 \\
154.338\end{array}$ & $\begin{array}{r}8.842 \\
181.276\end{array}$ & 149.015 & 84.864 & $\begin{array}{r}0.408 \\
85.360\end{array}$ & 75.907 \\
\hline Total & 27.851 .985 & 19.903.437 & 22.685 .306 & 21.571 .255 & 20.381.729 & 20.012.194 & 21.457.344 -1.3. \\
\hline
\end{tabular}

